\title{
Wind loads on heliostats and photovoltaic trackers of various aspect ratios
}

\author{
A. Pfahl| ${ }^{a,{ }^{*}}$, M. Buselmeier ${ }^{b}$, M. Zaschke ${ }^{b}$ \\ ${ }^{a}$ German Aerospace Center (DLR) \\ Solar Research \\ Pfaffenwaldring 39-40 \\ D - 70569 Stuttgart \\ Germany \\ ${ }^{b}$ Wacker Ingenieure \\ Wind Engineering Consultants \\ Gewerbestraße 2 \\ D - 75217 Birkenfeld \\ Germany
}

Available online at http://www.sciencedirect.com/science/article/pii/S0038092X1100209X

(c) 2011 The Authors. Published by Elsevier Ltd. Solar Energy Vol. 85, Issue 9, Sept. 2011, pp 2185-2201

doi:10.1016/j.solener.2011.06.006

\section{Abstract}

For the layout of solar trackers the wind loads on the structure have to be known. They can be calculated by using wind load coefficients given in literature. But so far these values are only valid for aspect ratios of the panel (width to height) of about 1.0. Therefore the wind load coefficients for heliostats of aspect ratios between 0.5 and 3.0 were determined to close this gap.

As solar trackers are exposed to the turbulent atmospheric boundary layer the turbulence of the approaching flow has to be modelled. As a reliable method at reasonable cost wind tunnel measurements were chosen. Solar trackers of $30 \mathrm{~m}^{2}$ panel size were investigated at a model scale of 1:20. Wind direction and elevation angle of the panel were varied to investigate especially the constellations at which the highest wind loads are expected (critical load cases). By spires and roughness elements a wind profile and a turbulence intensity of the modelled wind according to typical sites for solar trackers were achieved. The loads were measured by a high frequency force balance placed underneath the models. Additionally measurements of the pressure distribution on a panel with aspect ratio of 1.2 were performed to better understand the effects that lead to the peak values of the wind load coefficients.

A significant impact of the aspect ratio was measured. For the critical load cases the aspect ratio dependencies of the accordant peak wind load components were

* Corresponding author: Tel.: ++49 7116862 479, Fax: ++49 71168628032 ,

E-Mail: Andreas.Pfahl@dlr.de 
determined. By these the peak wind loads on solar trackers of varies aspect ratios can be calculated.

Regarding the single solar tracker components the main results are: Higher aspect ratios are advantageous for the dimensioning of the foundation, the pylon and the elevation drive but disadvantageous for the azimuth drive.

\section{Keywords}

heliostat, wind load, aspect ratio, PV tracker, central receiver, solar tower plant

\section{Nomenclature}

\begin{tabular}{|c|c|c|}
\hline A & mirror area & {$\left[\mathrm{m}^{2}\right]$} \\
\hline$b$ & width of mirror plane & [m] \\
\hline$c$ & wind load coefficient & {$[-]$} \\
\hline$C_{F, \text { meas }, \text { ra }}$ & measured wind force coefficient of aspect ratio $r_{a}$ & \\
\hline$c_{F, P e t}$ & $\begin{array}{l}\text { wind force coefficient according to } \\
\text { Peterka and Derickson (1992), only for } r_{2}=1\end{array}$ & [-] \\
\hline$c_{M, \text { meas,ra }}$ & measured wind moment coefficient of $r_{a}$ & \\
\hline$c_{M, P e t}$ & $\begin{array}{l}\text { wind moment coefficient according to } \\
\text { Peterka and Derickson (1992), only for } r_{a}=1\end{array}$ & \\
\hline $\begin{array}{l}C_{P y} \\
D\end{array}$ & $\begin{array}{l}\text { wind force coefficient of circular cylindrical pylon } \\
\text { diameter of pylon }\end{array}$ & \\
\hline$d_{r a}$ & aspect ratio $\left(r_{a}\right)$ dependency of peak values & \\
\hline$d_{r a, F, \text { meas }}$ & $\begin{array}{l}r_{a} \text { dependency of force gained by measurements, } \\
\text { see table } 2\end{array}$ & \\
\hline$d_{r a, F, P e t}$ & $\begin{array}{l}r_{a} \text { dependency of force according to } \\
\text { (Peterka and Derickson, 1992), see table } 2\end{array}$ & \\
\hline$d_{r a, M, \text { meas }}$ & $\begin{array}{l}r_{a} \text { dependent effective lever arm of moment gained } \\
\text { by measurements, see table } 2\end{array}$ & \\
\hline$d_{r a, M, P e t}$ & $\begin{array}{l}r_{a} \text { dependent effective lever arm of moment according } \\
\text { to (Peterka and Derickson, 1992), see table } 2\end{array}$ & \\
\hline$F$ & force caused by wind & \\
\hline$F_{d r a m, r a}$ & $\begin{array}{l}\text { calculated wind force of aspect ratio } r_{a} \\
\text { based on measurements with various } r_{a}\end{array}$ & \\
\hline$F_{\text {meas,ra }}$ & measured wind force of aspect ratio $r_{a}$ & J] \\
\hline$F_{P e t, r a}$ & $\begin{array}{l}\text { wind force of aspect ratio } r_{a} \text { according to } \\
\text { (Peterka and Derickson, 1992) }\end{array}$ & \\
\hline$F_{r a}$ & wind force at certain aspect ratio & V] \\
\hline$F_{X P a}$ & horizontal wind force of panel & \\
\hline$F_{X P y}$ & horizontal wind force of pylon & \\
\hline$h$ & height of mirror plane & \\
\hline$H$ & height of elevation axis & \\
\hline $\begin{array}{l}H_{P} \\
i\end{array}$ & height of elevation axis not wind shaded by panel & \\
\hline
\end{tabular}




\begin{tabular}{|c|c|c|}
\hline & characteristic lever arm & [m] \\
\hline M & moment caused by wind & [Nm] \\
\hline$M_{\text {dram,ra }}$ & $\begin{array}{l}\text { calculated wind moment at aspect ratio } r_{a} \\
\text { based on measurements with various } r_{a}\end{array}$ & [Nm] \\
\hline$M_{\text {meas }, \text { ra }}$ & measured wind moment at aspect ratio $r_{a}$ & [Nm] \\
\hline$M_{P e t, r a}$ & $\begin{array}{l}\text { wind moment at aspect ratio } r_{a} \text { according to } \\
\text { (Peterka and Derickson, 1992) }\end{array}$ & {$[\mathrm{Nm}]$} \\
\hline Mra & wind moment at certain aspect ratio & [Nm] \\
\hline$n$ & exponent of power law describing wind profile & \\
\hline$p_{d y n}$ & dynamic pressure & {$\left[\mathrm{N} / \mathrm{m}^{2}\right]$} \\
\hline$R$ & $\begin{array}{l}\text { gust factor (peak wind speed / mean wind speed, for } \\
2-3 \text { sec. gusts and } 18 \% \text { turbulence intensity } R=1.6 \text { ) }\end{array}$ & \\
\hline$r_{a}=b / h$ & aspect ratio width to height of mirror plane & [-] \\
\hline$v$ & mean wind speed at elevation axis height $H$ & {$[\mathrm{~m} / \mathrm{s}]$} \\
\hline$v_{\text {ref }}$ & mean wind speed at mean wind tunnel height $(100 \mathrm{~cm})$ & {$[\mathrm{m} / \mathrm{s}]$} \\
\hline$v(z)$ & mean wind speed at height $z$ & [m/s] \\
\hline$x$ & coordinate, horizontal, perpendicular to elevation axis, & at base \\
\hline$y$ & coordinate, horizontal, along elevation axis, at base & \\
\hline$z$ & coordinate, vertical upwards (azimuth axis); height & [m] \\
\hline$z_{\text {ref }}$ & reference height & [m] \\
\hline$\alpha$ & elevation angle of mirror plane, $0^{\circ}$ when horizontal & \\
\hline$\beta$ & wind direction, $0^{\circ}$ when perpendicular to elevation ax & \\
\hline$\rho$ & density of air & \\
\hline
\end{tabular}

\section{Introduction}

As photovoltaic (PV) and solar thermal power plants are getting more and more important for the world wide energy supply heliostats of central receiver power plants and PV trackers are build in rising quantities. The higher the quantities the more significant is a cost effective design of the structure. For their dimensioning the wind loads are decisive and therefore should be known as precise as possible.

An important characteristic of solar trackers is the aspect ratio of the panel. At the determination of the aspect ratio two contrary aims have to be taken into account: First, to reduce the height of the solar tracker and thus the average wind speed, wide panels would be favourable. Second, to avoid long lever arms and for to reach high field densities (assuming that the distance between the solar trackers is determined by the diagonal of the panel), square panels would be best. From investigations of simple plates it is known that the aspect ratio can have a significant influence on the wind loads (Sakamoto and Arie, 1983). For a cost effective design of solar trackers therefore the impact of their aspect ratio concerning wind loads has to be known. 
Peterka and Derickson (1992) have extensively investigated the wind loads on heliostats through boundary layer wind tunnel tests. By their report the wind load coefficients for the main wind load components are available. But they explicitly remark that the tested heliostats were nearly square in shape and that the impact of the aspect ratio is not known from the tests leading to their report (p. 13). Also recent publications are based only on heliostats with aspect ratio around 1 (Wang and Li, 2008; Wu et al., 2010). Therefore the aspect ratios (width/height) $0.5,1.0,1.2,1.5,2.0$ and 3.0 (see figure 1) were investigated. Although aspect ratios of 0.5 and 3.0 are usually not chosen for solar trackers these values were investigated to achieve more pronounced results which help to clearer understand the effects that are causing the aspect ratio dependencies.

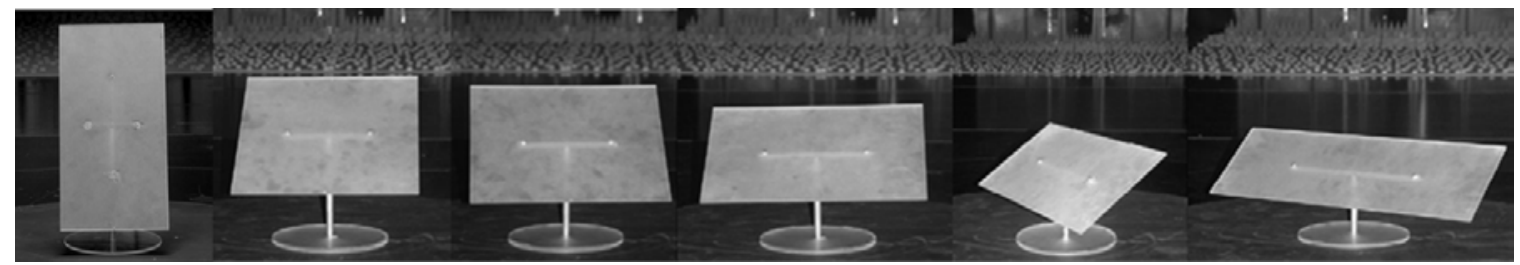

Figure 1: Heliostat models with aspect ratio 0.5, 1.0, 1.2, 1.5, 2.0 and 3.0

Background of the investigations is the development of a heliostat with hydraulic drive and a mirror area of $30 \mathrm{~m}^{2}$ (HydroHelio ${ }^{\mathrm{TM}}$ ). Before these investigations it was not possible to decide in a profound way which aspect ratio for the mirror plane should be chosen.

For uniformity reasons the coordinate system and the characteristic lengths are according to (Peterka and Derickson, 1992, p. 11), see figure 2.

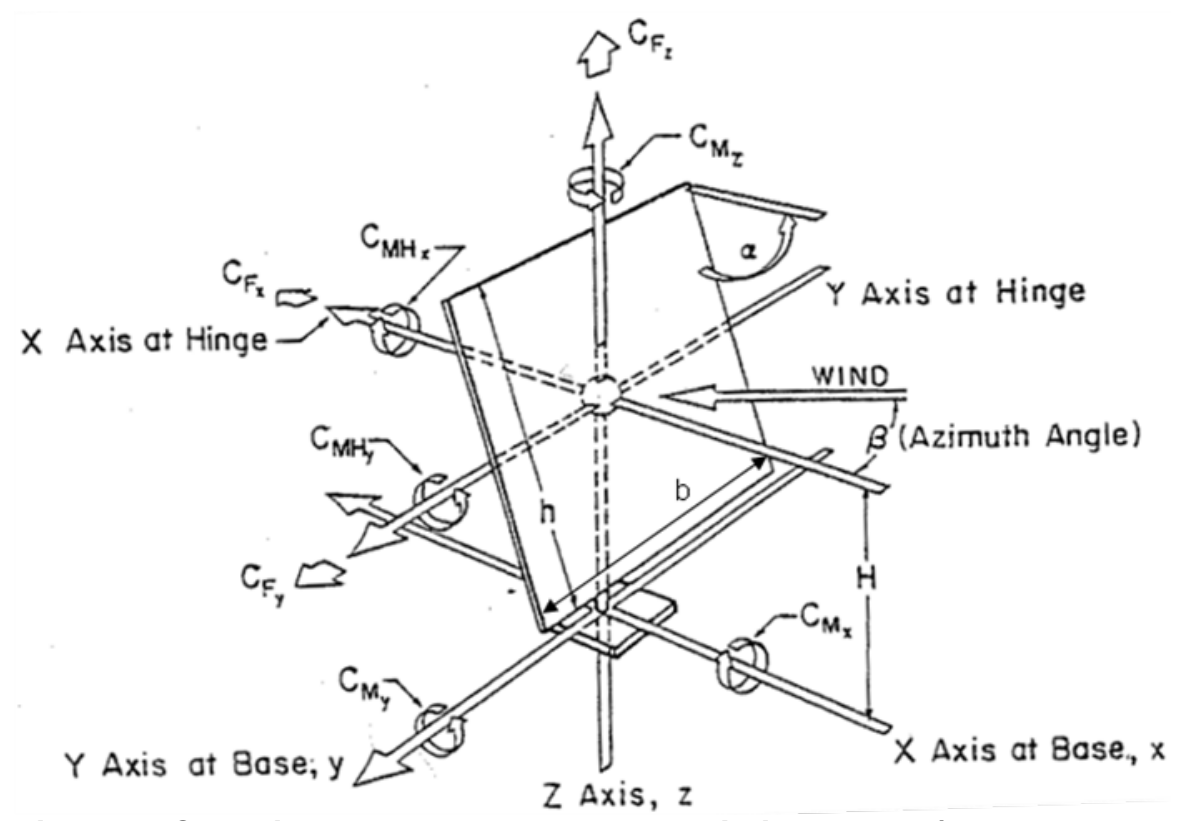

Figure 2: Coordinate system and characteristic lengths (Peterka and Derickson, 1992) 


\section{Selection of method and specifications}

\subsection{Selection of method}

Theoretically, the wind loads could be determined at real scale heliostat models exposed to atmospheric wind. But the low reproducibility of the wind conditions would make it almost impossible to compare the results of heliostats with different aspect ratio. At numerical calculations (computational fluid dynamics, CFD) and at physical wind tunnel tests in model scales this problem is avoided.

For the layout of solar trackers the peak values of the wind loads are decisive. Therefore CFD is only hardly suitable because especially the peak values of the wind load components are highly sensitive to turbulence (gustiness) in the attacking wind, as Peterka and Derickson (1992, p. 2) observed in their wind tunnel tests and which is also known for other structures (Hucho, 2002, chapter 3.7). Hence it is important that the turbulence of the attacking wind is appropriately modeled. For CFD this means that a turbulent inflow must be generated. Fröhlich (2006, pp. 207ff) gives an overview of possible methods. A method for synthetic turbulence generation which is already implemented at a commercial tool is the vortex method (Sergent, 2002; Mathey et al. 2006). Further more it must be ensured that the turbulence doesn't dissipate before reaching the investigated body. At the common RaNS (Reynolds averaged Navier-Stokes) simulations the averaging eliminates turbulence structures in the flow (Fröhlich, 2006, p. 16ff). The used turbulence models account for this only at micro scale. Thus only simulation approaches at which at least the largest turbulence structures are captured are suitable (especially LES, Large Eddy simulation or DES, Detached Eddy Simulation) (Spalart, 2000). Further more it is necessary to run the simulation for at least $10 \mathrm{~min}$ in real scale to determine the peak values of the wind load coefficients (Cook and Mayne 1980). In combination with the fine grid which is necessary for LES or DES this would mean a not feasible high amount of computational time.

For some cases it is possible to determine the peak loads by just multiplying the loads gained at attacking wind of (almost) no turbulence (measured or calculated) with the square of the gust factor $R$ accordant to the turbulence intensity of the site (for a typical solar site turbulence intensity of $18 \% R=1.6$ ) (Peterka and Derickson, 1992, pp. 5ff). But this approach does not work well for cases at which a wind load component is sensitive - first - to a change of the wind direction or - second - to an unequal pressure distribution on the mirror plane.

The first is the case for example for the hinge moment $M_{H y}$ at stow position (horizontal mirror plane). The mean value for this position is near zero while the peak value caused by a temporarily sideward (to the panel) wind attack is not. Peterka and Derickson (1992, p. 18) measured a ratio of peak to mean value of 10 for this case while $R^{2}$ was only 2.56 . Also mean values can be sensitive to the 
turbulence intensity of the attacking wind (Peterka and Derickson, 1992, pp. $13 \mathrm{ff})$. This is confirmed by the comparison of CFD simulation and wind tunnel measurement of $\mathrm{Wu}$ and Wang (2008) at which significant discrepancies occurred.

The second is the case for example for $M_{H y}$ at upright mirror orientation and frontal wind attack. For steady wind the force on the upper and lower part of the mirror plane is relatively equal which causes only a low moment about the elevation axis. But at realistic turbulent approaching flow temporarily unequal pressure distributions (compare figure 3 ) are causing peak hinge moments that are at the measurements of Peterka and Derickson (1992, p. 18) 12 times and in this study 9 times higher than the mean loads. Also in this case CFD or wind tunnel measurements at attacking wind of no or low turbulence in combination with the gust factor approach would not lead to realistic results for the peak values.
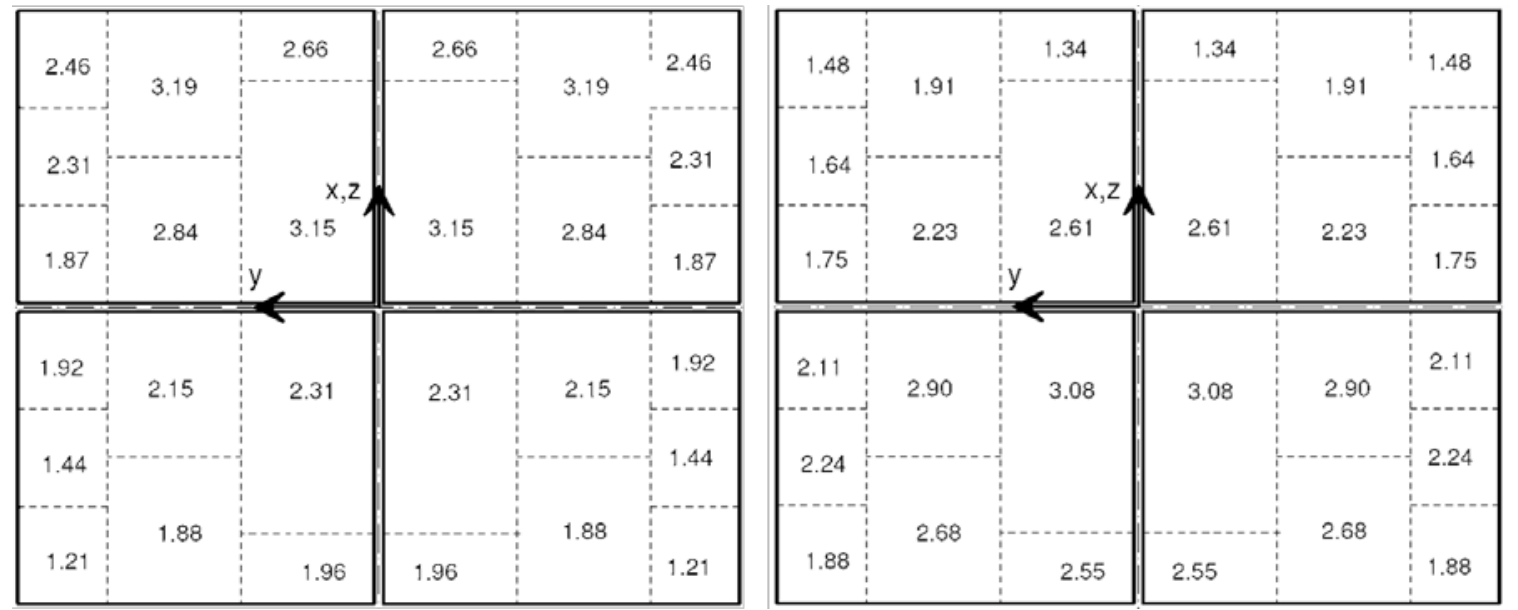

Figure 3: Pressure coefficient distribution for aspect ratio 1.2 at point in time with maximum (left) and minimum (right) peak $M_{H y}$ with $\alpha=90^{\circ}$ and $\beta=0^{\circ}$ (load case 1)

For these reasons boundary layer wind tunnel tests were chosen to determine the impact of the aspect ratio on the wind load components. At them the wind conditions can be defined reproducible at comparably reasonable cost.

\subsection{Specifications}

The mirror area $\left(A=30 \mathrm{~m}^{2}\right)$ and the distance of the mirror plane to the ground at upright orientation $(H-1 / 2 h=0.4 \mathrm{~m})$ was the same for all aspect ratios. This means that the elevation axis height $H$ decreases with the aspect ratio. Hence the wind load coefficients are calculated on the base of the wind speed $v$ at elevation axis height $H$ to obtain better comparability. Especially for the overturning moments $M_{x}$ and $M_{y} H$ is of influence. Therefore $H$ is explicitly given in the accordant formulas (table 2). For the other wind load components $H$ is of much smaller impact. Nevertheless for ratios of ground distance to mirror area $(H-1 / 2 h) / A$ much different to the value of this study the results might not be valid. 
In reality the mirror plane is divided by thin gaps between the facets but these are of negligible influence on the wind loads as Wu et al. (2010) have shown. The scale of the models is 1:20. Exemplarily a drawing of the model with aspect ratio 1.2 is given by figure 4 .

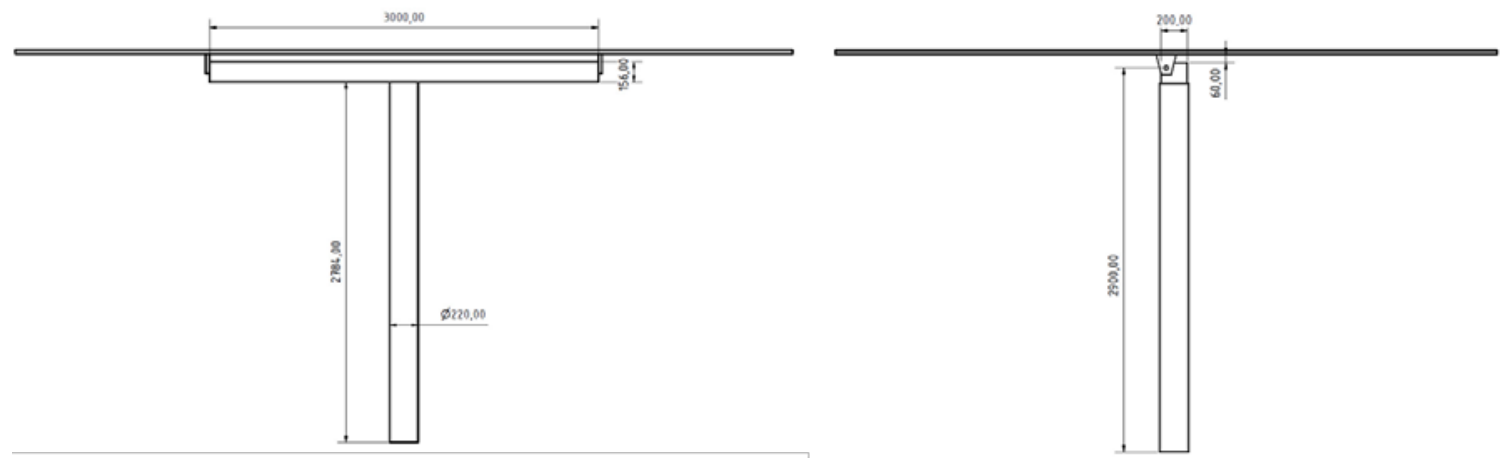

Figure 4: Sketch of heliostat model with aspect ratio 1.2

The wind load components differ with the elevation of the panel $\alpha$ and of the wind direction $\beta$. The combinations of $\alpha$ and $\beta$ that lead to the maximal values of the wind load components have to be mainly considered the dimensioning of solar trackers (Peterka and Derickson, 1992, p. 17f). These relevant load cases were investigated (see table 2).

\section{Experimental procedure}

\subsection{Similarity}

In order to obtain realistic wind loads by means of wind tunnel tests the most significant modelling laws have to be accounted for. These are mainly the geometric similarity of the model and the similarity of the approaching flow (Plate 1982).

Wind events can be classified into micrometeorological and macrometeorological wind events. Macrometeorological wind events are mainly caused by changes in climate and appear in periods down to one hour. Micrometeorological wind events are caused mainly by obstacles on the ground that disturb the wind and appear in periods up to $10 \mathrm{~min}$. The range between $10 \mathrm{~min}$ and $1 \mathrm{~h}$ is the so called "spectral gap" with only rare wind events.

For to determine the influence of the fluctuations caused by micrometeorological wind events in interaction with the investigated structure the loads must be measured in a time interval of minimum 10min (at real scale) to capture all possible micrometeorological wind events. For the determination in wind tunnels 
the micrometeorological fluctuations must be modeled according to the length scale. Also the needed time for the measurements scales with the length scale. Therefore for example for the used length scale of 1:20 and assuming the 10minmean-wind-speed a duration of every measurement of 30 seconds was necessary.

The more often the 10min-measurement would be repeated the higher would be the maximal peak value of all experiments. By extreme value statistics (Cooke and Mayne, 1980) it is possible to determine the maximal peak value that would appear within an arbitrary period of time. In building codes usually a period of 50 years is used as a standard. Therefore the wind load coefficients given here are as well the 50-year-peak-values. By the combination of the maximal expected 10 min-mean-wind-speed within 50 years ("50 year event") of the site with the 10 min-peak-load-coefficient for 50 years the maximal expected load can be determined. To exclude that the structure would, to say, collapse every 50 years in average a safety factor has to be foreseen.

With the geometric scale of 1:20 of the wind tunnel models (see figs. 1 and 7) it was ensured that the models were big enough in order to deliver highly resolved and accurate measurement data but still of an appropriate size in order to avoid any wind-tunnel blockage that could influence the measurements (the wind tunnel cross section is $1.80 \mathrm{~m} \times 2.00 \mathrm{~m}$ ). The models were equipped with a mechanism allowing to adjust their elevation angle and mounted on a turntable which made it possible to rotate them in order to model the different wind directions.

The similarity of the approaching flow depends crucially on the upstream surface characteristics. For the present case it is appropriate not to consider any individual obstacles like buildings or vegetation in the vicinity of the heliostat but to characterize the surrounding landscape by its surface roughness. This is reasonable because the results of the investigation should be as general as possible and not be limited to one particular case. In the laboratory, the roughness is realized by placing vortex generators (spires) at the entrance to the wind tunnel and roughness elements along the flow upwind of the model. A schematic section through the atmospheric boundary layer wind tunnel used for the present investigation is given in figure 5 . 


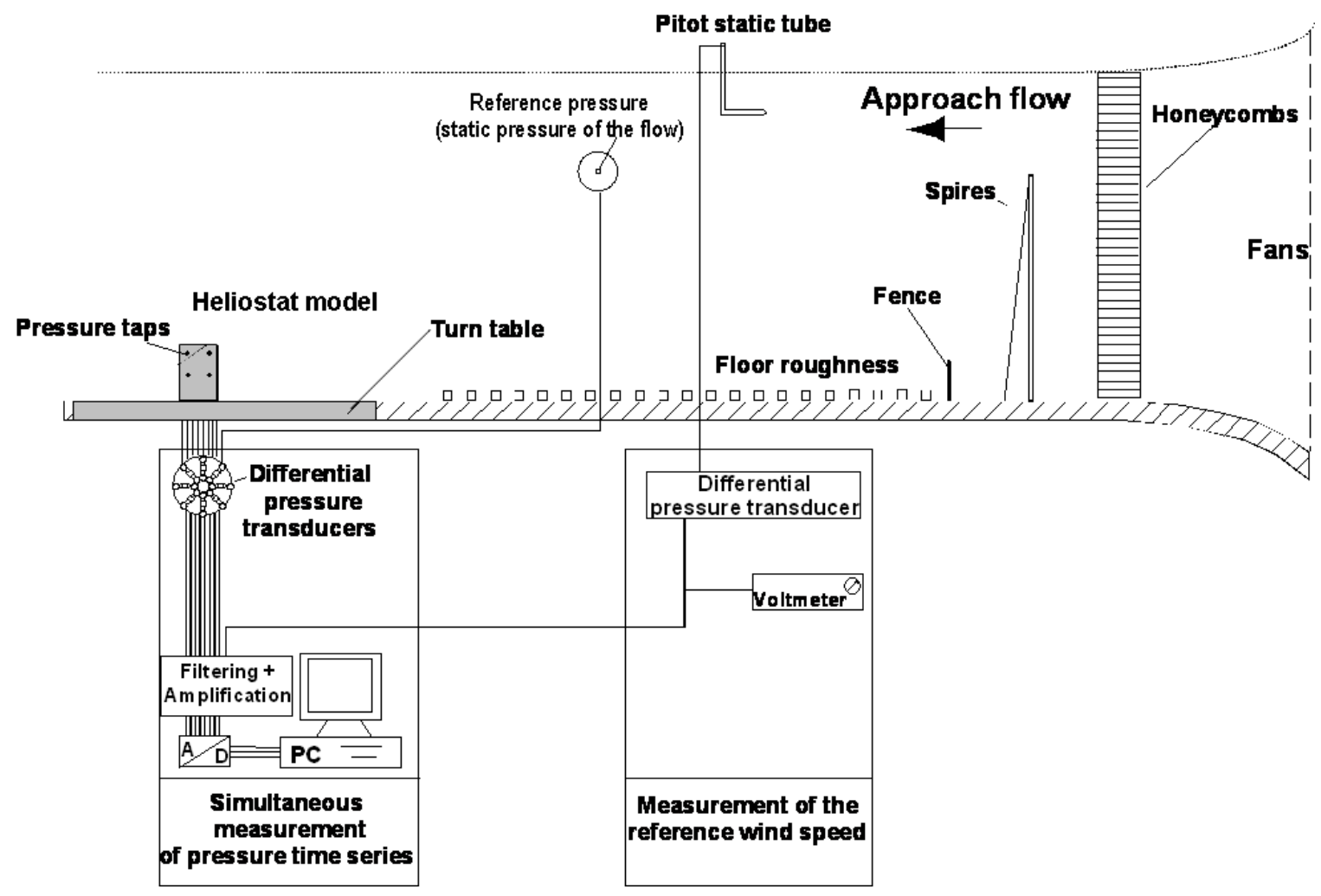

Figure 5: Schematic section through the atmospheric boundary layer wind tunnel used for the present investigation.

In wind engineering it is common practice to describe the vertical distribution of mean wind speed $v(z)$ using the power law approach (see formula (1) and figure 6 (left)).

$$
\frac{v(z)}{v\left(z_{\text {ref }}\right)}=\left(\frac{z}{z_{\text {ref }}}\right)^{n}
$$

The exponent $n$ is a function of surface roughness. Besides the mean wind profile, the roughness also determines the turbulence characteristics of the boundary layer flow above it. Typical surroundings of solar power plants are open countries with single trees and buildings. The corresponding value for $n$ in the power law approach is $n=0.15$ (Peterka and Derickson, 1992, p. 6). It was therefore decided to adjust the roughness elements and vortex generators in the wind tunnel in order to reproduce the corresponding profile. The distance between the vortex generators and the model test section is about 8 metres. This length was observed to be big enough in order to guarantee the development of a thick, equilibrated boundary layer.

A further function of surface roughness is the turbulence intensity which is defined as the standard deviation of the wind speed fluctuations related to the mean wind speed. The elevation axis of the models varies between $0.10 \mathrm{~m}$ (for 
$r_{a}=3$ ) and $0.22 \mathrm{~m}$ (for $r_{a}=0.5$ ) at model scale. At this height range a turbulence intensity between $17.3 \%$ and $18.2 \%$ was measured in the wind tunnel (figure 6 , right). The difference of $0.9 \%$ is of no significant influence (compare figure 3 of (Peterka and Derickson, 1992)).
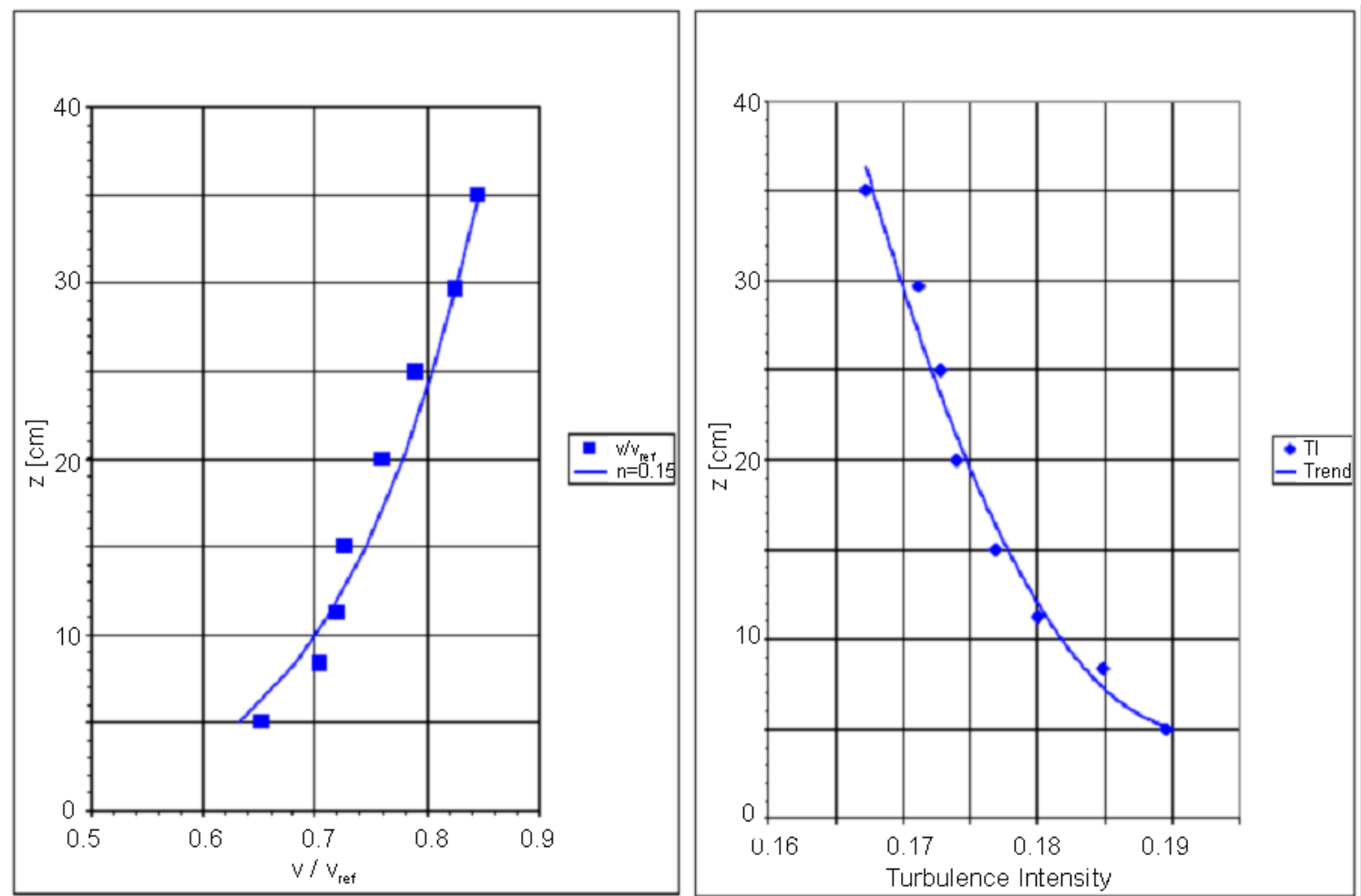

Figure 6: Wind profile (left) and turbulence intensity profile (right) of the simulated atmospheric boundary layer

A further modeling requirement is to ensure equality of the Reynolds numbers in laboratory and nature. Especially for curved shapes like circular cylinders or spheres or for the flow through openings the Reynolds number similarity is important because for these cases the Reynolds number influences the position of the separation point and thus the wind induced pressure distribution. However, for sharp edged bodies the separation point (or line) is defined by the edges and therefore is fix and independent of the Reynolds number, provided a certain minimum Reynolds number is exceeded (Plate 1982). At wind tunnel measurements at a high pressure wind tunnel with a wide variability of the Reynolds number it could be shown that the dependency of the wind load coefficients of heliostats on the Reynolds number is negligible even for solar trackers with circular cylindrical torque tube which is exposed to the wind at horizontal panel at stow position (to be published soon).

\subsection{Force balance}


For the determination of the aero dynamical wind force coefficients a high frequency force balance was used. With it the bearing forces at the pylon feet of the model can be measured directly. Besides the time-averaged reaction forces also the fluctuating fractions can be measured. To exclude distortions of the fluctuating load reactions it is important that the resonance frequency of the force balance in the three force directions is higher than the frequency of the actuating force. If the range of the frequencies of the actuating force would be in the range of the resonance frequency of the balance resonance raise would appear which would lead to too high measuring results. The force balance therefore must be as stiff as possible with high resonance frequency. Usually it is sufficient to adjust the balance in a frequency range higher $100 \mathrm{~Hz}$. The fixing of the wind tunnel model on the measuring table was realized with vacuum technique: By depression the model was sucked on the measuring table.

With the force balance it is possible to determine the forces and moments at the pylon feet. But the hinge moment at elevation axis height can not be directly measured. However it is possible to calculate it by (2) with sufficient accuracy assuming the following: The total horizontal force (measured at the pylon feet) $\left(F_{X}\right)$ is composed by the horizontal load on the pylon $\left(F_{X P Y}\right)$ and by the horizontal load on the panel $\left(F_{X \mathrm{~Pa}}\right)(5)$. The load on the pylon can be calculated using the load coefficient for circular cylinders $c_{P y}=0.7$ (3). Thereby only the part of the pylon which is not wind protected by the panel $\left(H_{P}\right)$ has to be considered (4).

$$
M_{H y}=M_{y}-F_{x P a} \cdot H-F_{x P y} \cdot \frac{H_{P}}{2}
$$

with

$$
\begin{aligned}
& F_{x P y}=c_{P y} \cdot \frac{\rho}{2} \cdot v^{2} \cdot H_{P} \cdot D \\
& H_{P}=H-\sin (\alpha) \cdot \frac{h}{2} \\
& F_{x P a}=F_{x}-F_{x P y} .
\end{aligned}
$$

\subsection{Pressure measurements}

In addition to the measurements with the force balance pressure measurements were performed for a heliostat with the most common aspect ratio of 1.2 and with formed back structure (figure 7). The corresponding model was constructed using sophisticated three-dimensional printing technologies. The panel was built as a pressure measurement module. The mean and the fluctuating wind pressure on front and back side of the panel could be directly measured as a function of wind direction and elevation angle. The measurements were performed simultaneously on front and back side and throughout the entire surface area of the panel in order to be able to determine the differential pressure directly. The resulting dimensionless wind pressure coefficients (cp-values) 
describe the relation between the measured resulting pressures acting on the panel and the dynamic pressure of the undisturbed flow at elevation axis height $H$.

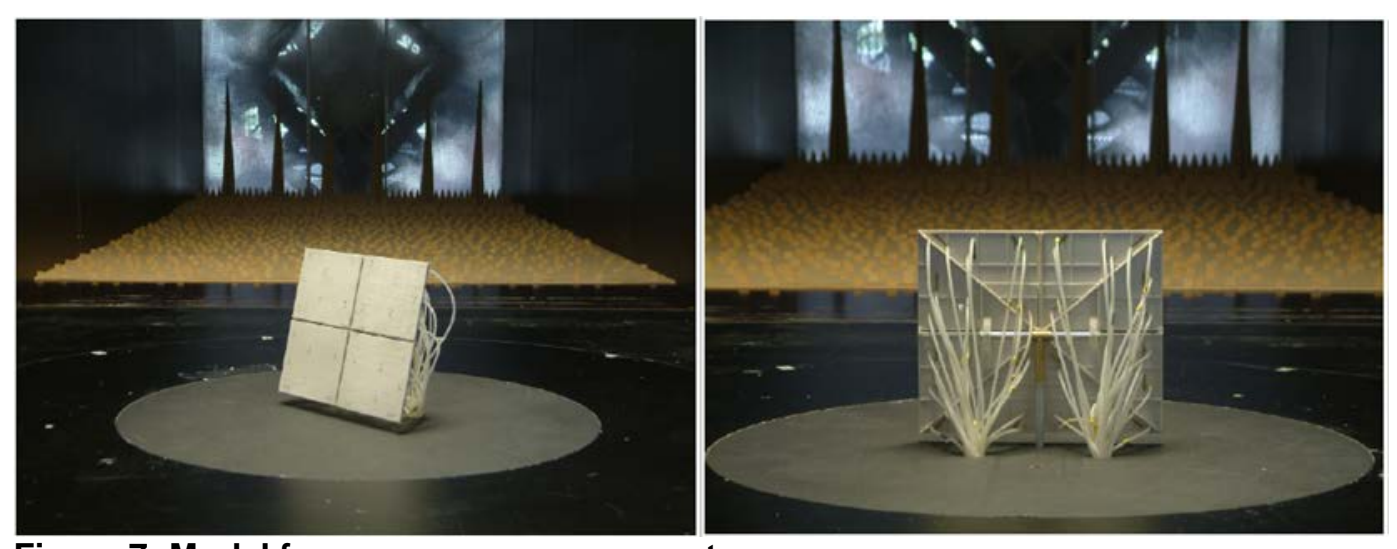

Figure 7: Model for pressure measurements

On each side of the panel 28 taps for the pressure measurements were collocated, typically $1 \mathrm{~mm}$ in diameter. The mirror panel consists of four facets "A" - "D" (figure 8). Each facet was divided into seven sections with one pressure tap delivering an approximately representative value for the corresponding section. For facet "A" the positions of the measuring points are given in table 1. The positions of the measuring points of the other sections follow symmetry. 


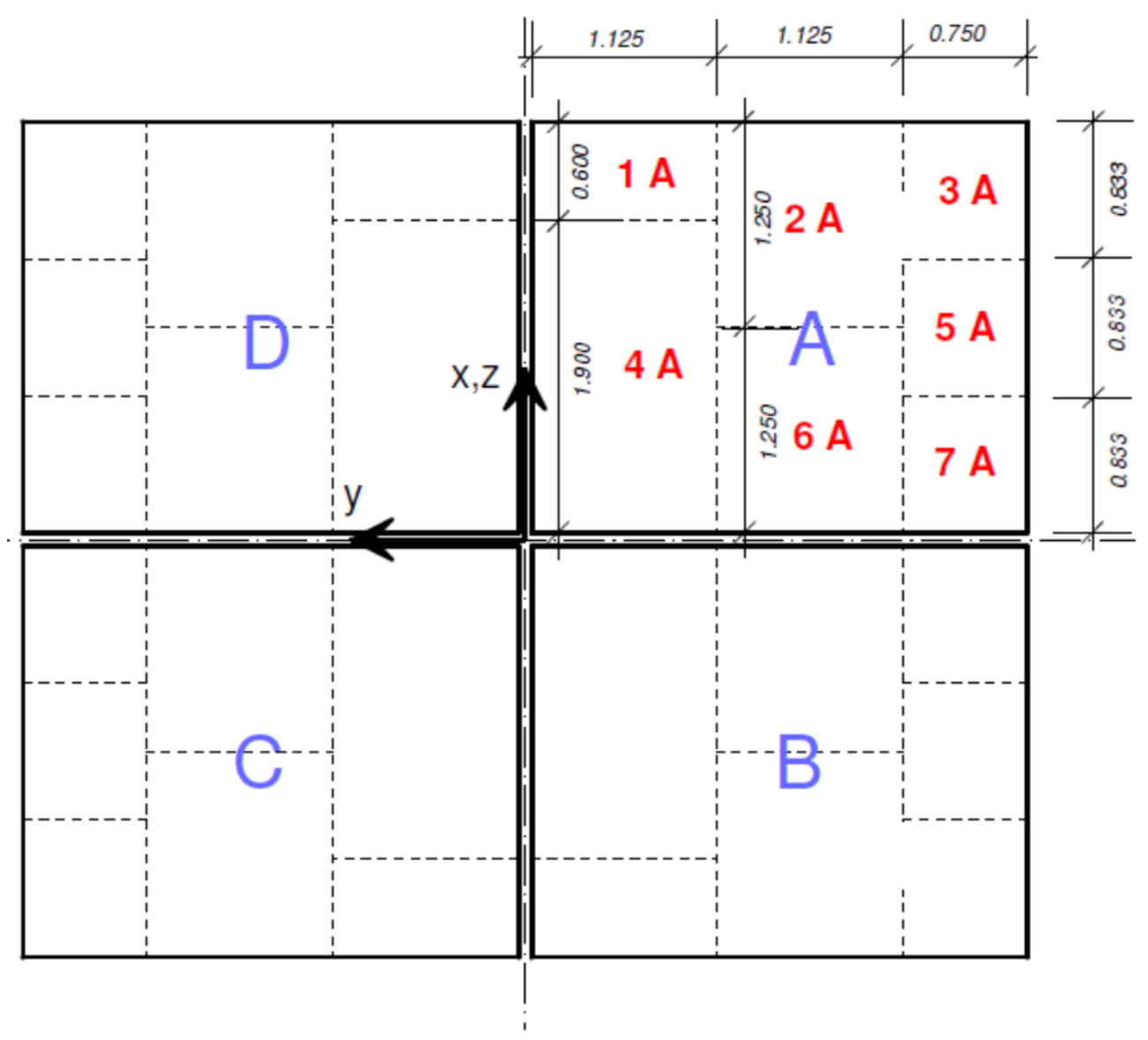

Figure 8: Sections of pressure measurements at four facets "A" - "D"

Table 1: Positions of measuring points for facet $A$

\begin{tabular}{|c|c|c|}
\hline measuring point & $\mathrm{x}[\mathrm{m}]$ & $\mathrm{y}[\mathrm{m}]$ \\
\hline 1 A & 2.30 & -0.50 \\
2 A & 1.90 & -1.80 \\
3 A & 2.30 & -2.75 \\
4 A & 0.90 & -0.50 \\
5 A & 1.40 & -2.75 \\
6 A & 0.90 & -1.80 \\
7 A & 0.50 & -2.75 \\
\hline
\end{tabular}

For load cases at which a symmetric pressure distribution can be assumed only half of the panel was measured to reduce the amount of pressure hoses and thus the distortion of the flow (see figures 3, 15 and 18).

\section{Definitions of wind load coefficients}

The following correlations lead to the definitions of the wind load coefficients: 


$$
\begin{aligned}
& F \sim p_{d y n}=\frac{\rho}{2} \cdot v^{2} \\
& F \sim A \\
& M \sim F \\
& M \sim l
\end{aligned}
$$

According to (6) - (9) and assuming an aspect ratio dependency the wind loads in the three coordinate directions are calculated in general by

$$
\begin{aligned}
& F_{i, r a}=c_{F i} \cdot \frac{\rho}{2} \cdot v^{2} \cdot A \cdot d_{r a, F i} \\
& M_{i, r a}=c_{M i} \cdot \frac{\rho}{2} \cdot v^{2} \cdot A \cdot d_{r a, M i}
\end{aligned}
$$

with $i$ indicating the coordinate direction $x, y$ or $z$.

The correlations of the wind load components used by Peterka and Derickson (1992, p. 10) can be expressed by

$$
\begin{aligned}
& F_{i, P e t, r a}=c_{F i, P e t} \cdot \frac{\rho}{2} \cdot v^{2} \cdot A \cdot d_{r a, F i, P e t} \\
& M_{i, P e t, r a}=c_{M i, P e t} \cdot \frac{\rho}{2} \cdot v^{2} \cdot A \cdot d_{r a, M i, P e t}
\end{aligned}
$$

with the accordant aspect ratio dependencies listed in table 2. They are intended to be valid only for $r_{a}=1$.

For to be able to compare the wind load coefficients of the measurements with the ones of Peterka and Derickson (1992) they are defined by

$$
\begin{aligned}
& F_{i, \text { meas }, r a}=c_{F i, \text { meas }, r a} \cdot \frac{\rho}{2} \cdot v^{2} \cdot A \cdot d_{r a, F i, \text { Pet }} \\
& M_{i, \text { meas }, r a}=c_{M i, \text { meas }, r a} \cdot \frac{\rho}{2} \cdot v^{2} \cdot A \cdot d_{r a, M i, P e t}
\end{aligned}
$$

using the same aspect ratio dependencies.

By the measurements new aspect ratio dependencies were gained (see table 2). With them the peak wind loads can be calculated for various aspect ratios if the wind load coefficients for aspect ratio $r_{a}=1$ are known by

$$
\begin{aligned}
& F_{i, d r a m, r a}=c_{F i, \text { meas }, r a=1} \cdot \frac{\rho}{2} \cdot v^{2} \cdot A \cdot d_{r a, F i, \text { meas }} \\
& M_{i, \text { dram }, r a}=c_{\text {Mi,meas }, r a=1} \cdot \frac{\rho}{2} \cdot v^{2} \cdot A \cdot d_{r a, \text { Mi,meas }} .
\end{aligned}
$$




\section{Results and discussion}

\subsection{General}

By the diagrams of this section the wind load coefficients times the aspect ratio dependencies

- according to (Peterka and Derickson, 1992), using (12) and (13),

- of the measurements, using (14) and (15) and

- according to the aspect ratio dependencies gained by the measurements using (16) and (17)

related to the aspect ratio dependencies according to (Peterka and Derickson, 1992) for $r_{a}=1$ (see table 2) are compared.

The correlations given by Peterka and Derickson (1992, p. 10) are intended to be valid for all angles of attack and not to be exclusive for special load cases. Furthermore they are only valid for squared heliostats (p. 13). So they did not intend to give aspect ratio dependencies of the wind load coefficients. But for the wind moments an effective lever arm is accounted for according to (9). These lever arms are aspect ratio dependent and therefore an aspect ratio dependency is implicitly given by their formulas for the wind moments which is illustrated in the diagrams for comparison (also for the wind forces for uniformity reasons).

The values of Peterka and Derickson (1992) for $r_{a}=1$ are mostly considerably higher than measured by the authors. If a heliostat model as described in (Peterka et al., 1986, p. 15) was used part of the reason would be the wide gaps between the three vertical facets. By wind tunnel tests with a heliostat model with two vertical facets and a wide gap in between performed by the authors an increase of the wind loads could be partly measured (to be published soon).

The aspect ratio dependencies used in (16) and (17) and given in table 2 represent fitting curves of the measured data (see figures 9-14, 16, 17 and 1922). The fitting was realized by multiplying an appropriate factor and by multiplying the aspect ratio by the power of an appropriate exponent. $H, h$ and $b$ can be expressed also by $r_{a}$ (formulas (19) - (21)). But for clearness and better comparability with the values of Peterka and Derickson (1992) they are partly given explicitly in this section. The exponents and factors are rounded to avoid the impression of an unrealistic high accuracy which is not attainable for peak wind loads.

Please note that different turbulence intensity and unusual flow conditions (for example caused by surrounding buildings or for sites at hilltops), unusual distinctive back structures of the mirror plane or of the torque tube, significantly 
different relative distance of the mirror plane to the ground at upright position and dynamical effects which are design dependent and not considered here, can lead to different wind loads. In these cases specific wind tunnel tests are necessary.

\section{$5.2 F_{X}$ - horizontal force perpendicular to elevation axis}

At load case 1 the heliostat is similar to a vertical flat plate with a gap to the ground. For free standing plates on ground, the wind force coefficient decreases with the aspect ratio for aspect ratios < 5 (Sakamoto and Arie, 1983; Letchford and Holmes, 1994). For slightly lifted plates this effect is little reduced (ESDU 89050, figure 7c; Leder and Geropp, 1993). In accordance (but more pronounced) a reduction of $F_{X}$ for increasing aspect ratio was measured (figure 9).

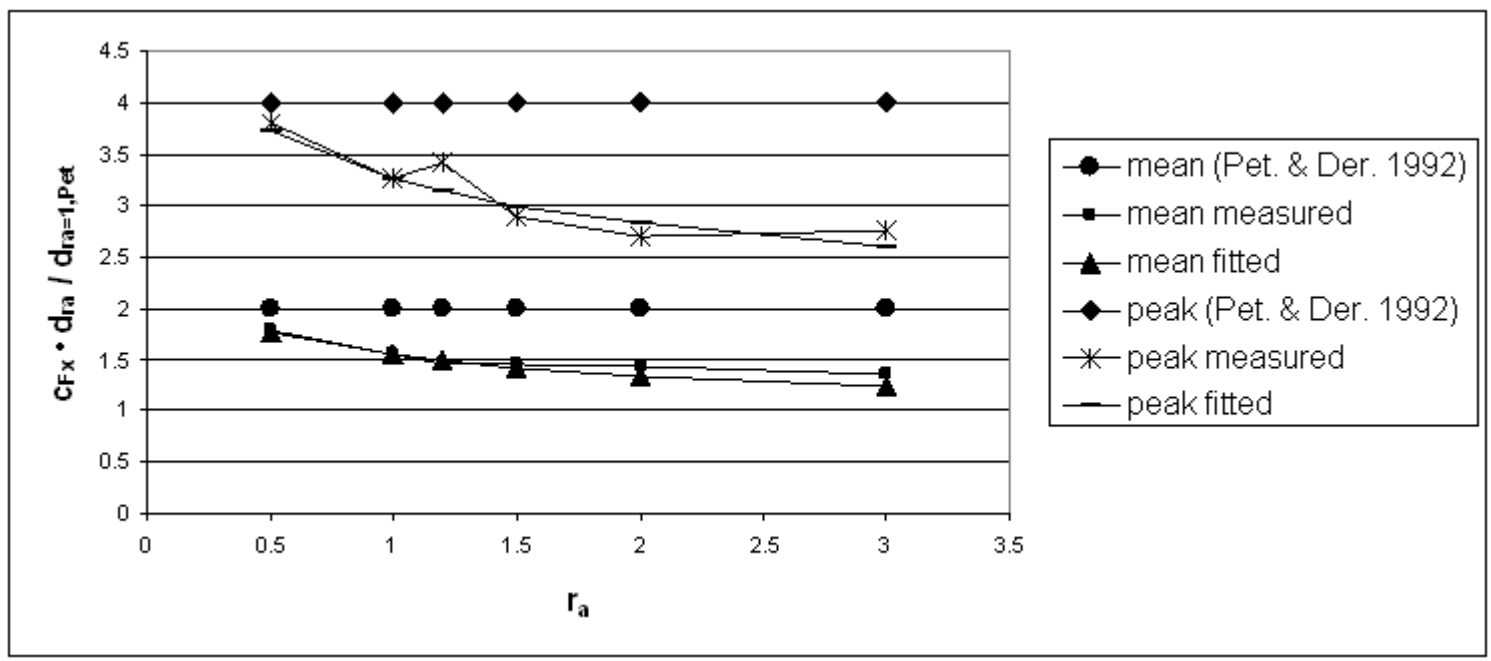

Figure 9: $c_{F x} \cdot d_{r a} l d_{r a=1, \text { Pet }}$ at load case 1

The effects causing the decrease of $F_{x}$ with the aspect ratio at load case 1 are also valid in a reduced manner (because of the smaller area of attack of the projection of the panel in wind direction) for load case 2 (figure 10). 


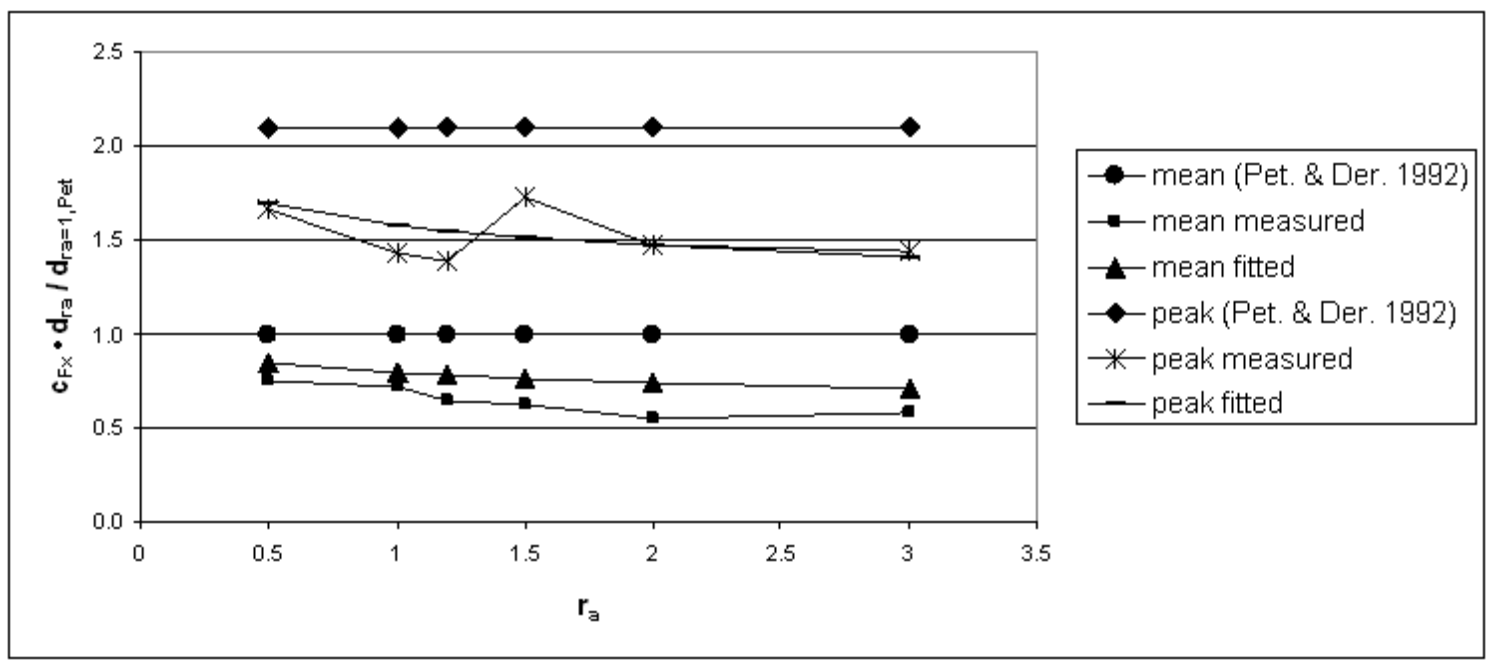

Figure 10: $c_{F x} \cdot d_{r a} l d_{r a=1, \text { Pet }}$ at load case 2

At load case 4 the panel is horizontal which means that the cross bar is directly exposed to the wind which increases with the aspect ratio as well as the frontal edge of the panel. Therefore $F_{X}$ increases with the aspect ratio (figure 11).

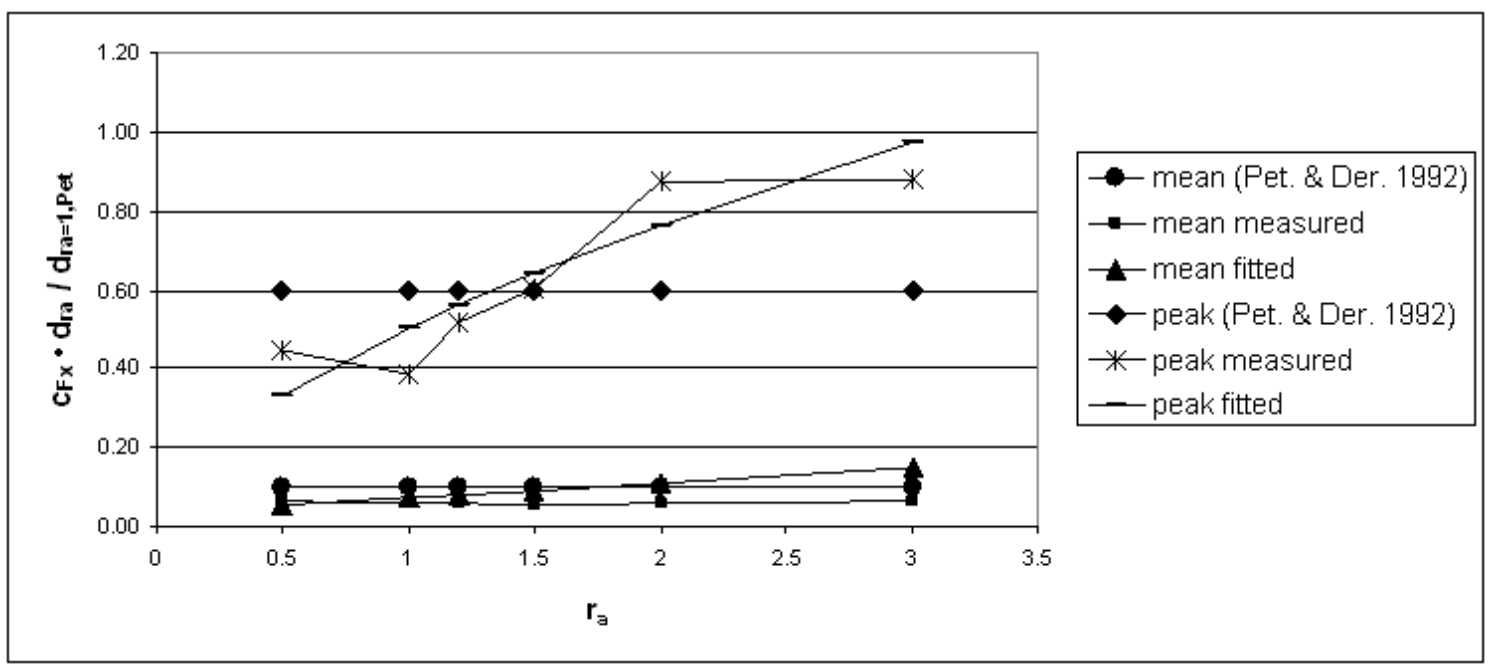

Figure 11: $c_{F x} \cdot d_{r a} / d_{r a=1, \text { Pet }}$ at load case 4

\section{3 $\quad F_{y}$-horizontal force along elevation axis}




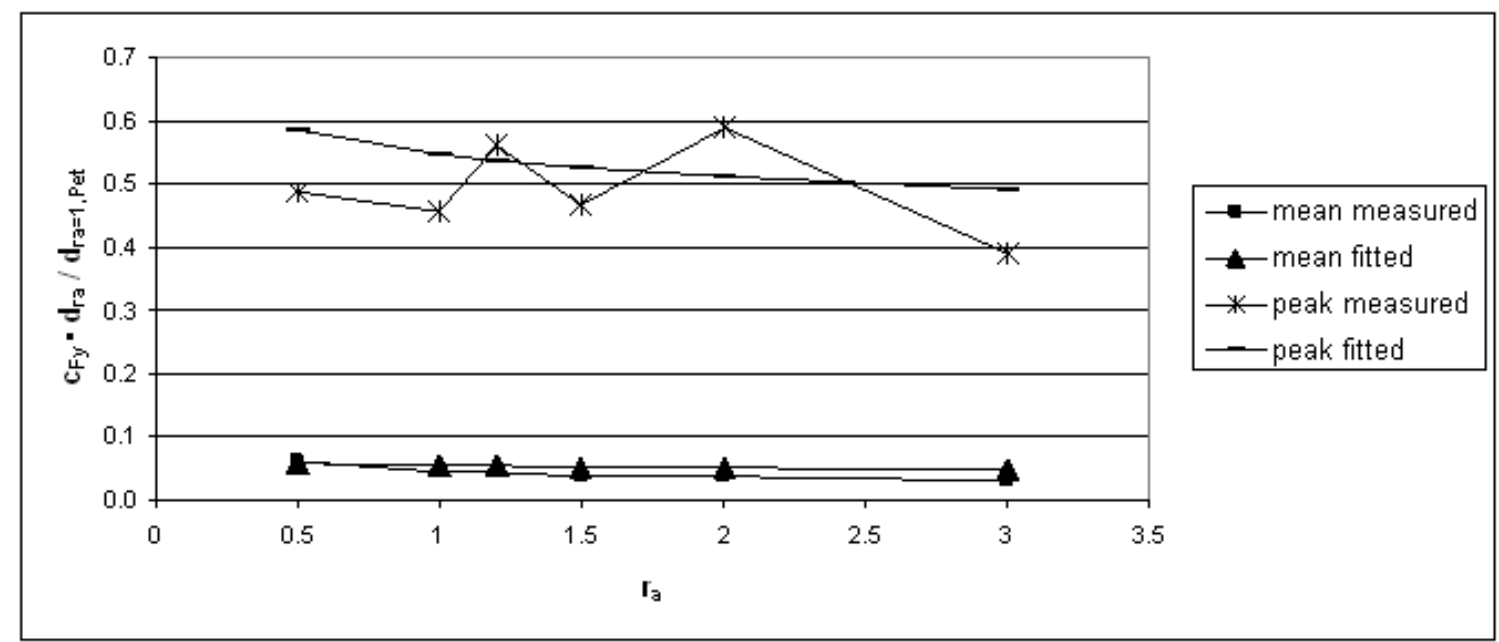

Figure 12: $c_{F y} \cdot d_{r a} l d_{r a=1, \text { Pet }}$ at load case 5

The values of $F_{y}$ at load case 5 decrease because the area of attack (pylon and frontal edge of the panel) decrease with increasing aspect ratio (figure 12).

\section{$5.4 F_{z}$ - vertical force}

The absolute values of $F_{z}$ at load case 2 decrease slightly with the aspect ratio (figure13). The reason might be that for bigger width $b$ the gusts of maximal wind speed cover a smaller portion of the mirror plane.

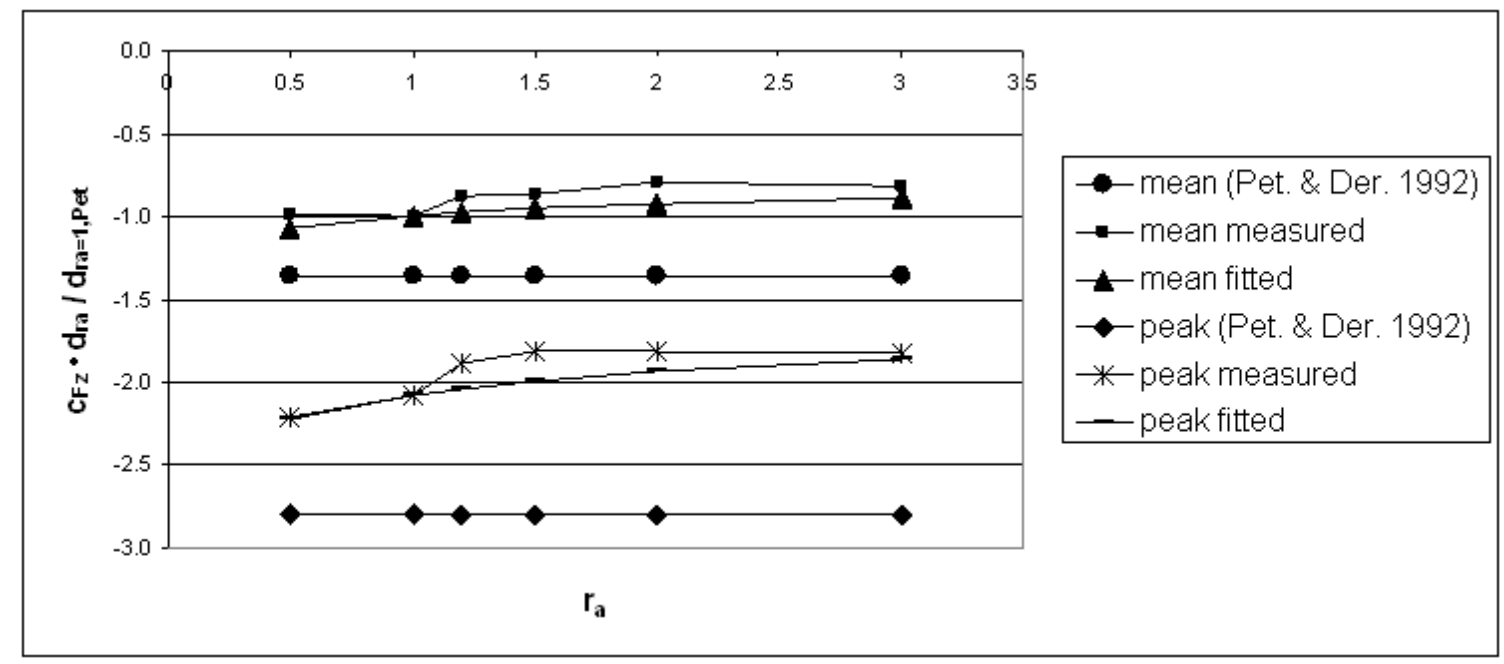

Figure 13: $c_{F z} \cdot d_{r a} / d_{r a=1, P e t}$ at load case 2

At load case 4 the mean wind has no component in $z$ direction. Therefore the mean values of $F_{z}$ are very low (figure 14). The peak values are caused by temporarily sideward wind attack which causes high pressure values at the frontal edge (figure 15). Since this edge increases with the aspect ratio $F_{Z}$ increases as well. The high differences to (Peterka and Derickson, 1992) particularly at this case are not clear. 


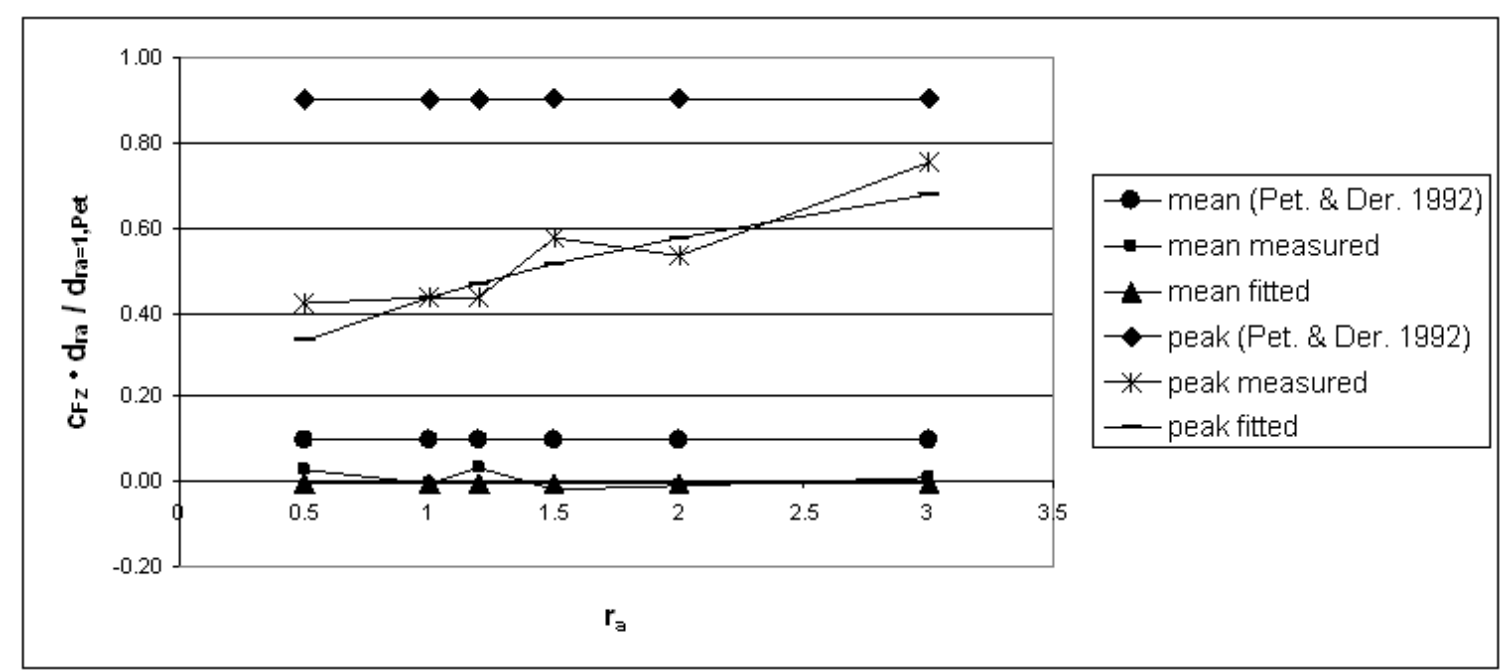

Figure 14: $c_{F z} \cdot d_{r a} / d_{r a=1, P e t}$ at load case 4
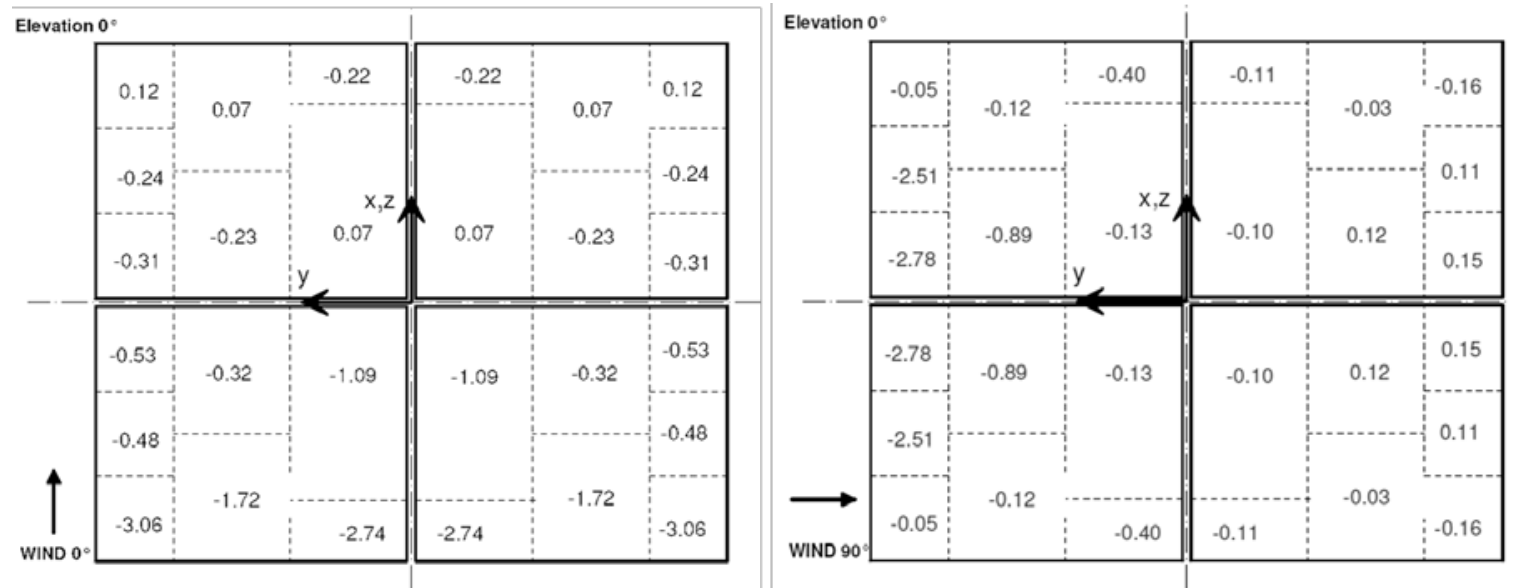

Figure 15: Pressure coefficient distribution for aspect ratio 1.2 at point in time with peak $F_{z}$ with $\alpha=0^{\circ}$ and $\beta=0^{\circ}$ (load case 4) (left) and peak $M_{x}$ with $\alpha=0^{\circ}$ and $\beta=90^{\circ}$ (load case 5) (right)

\section{$5.5 M_{x}$ - moment at pylon feet about x axis}

The values of $M_{x}$ at load case 5 (figure 16) are lower than of $M_{y}$ at load case 4 (figure 21) because of the orientation of the crossbar along with the elevation axis which leads to a smaller area of wind attack. Similar to $F_{z}$ the peak values of $M_{x}$ are caused by a zone of high pressure at the frontal edge (figure 15 right). For wind moments this leads to an almost constant aspect ratio dependency (compare figure 24) - also for at load case 5 (figure 16).

At (Peterka and Derickson, 1992) the correlation of $M_{x}$ is given but no values of the coefficient. Therefore they are missing in the diagram (figure 16). 


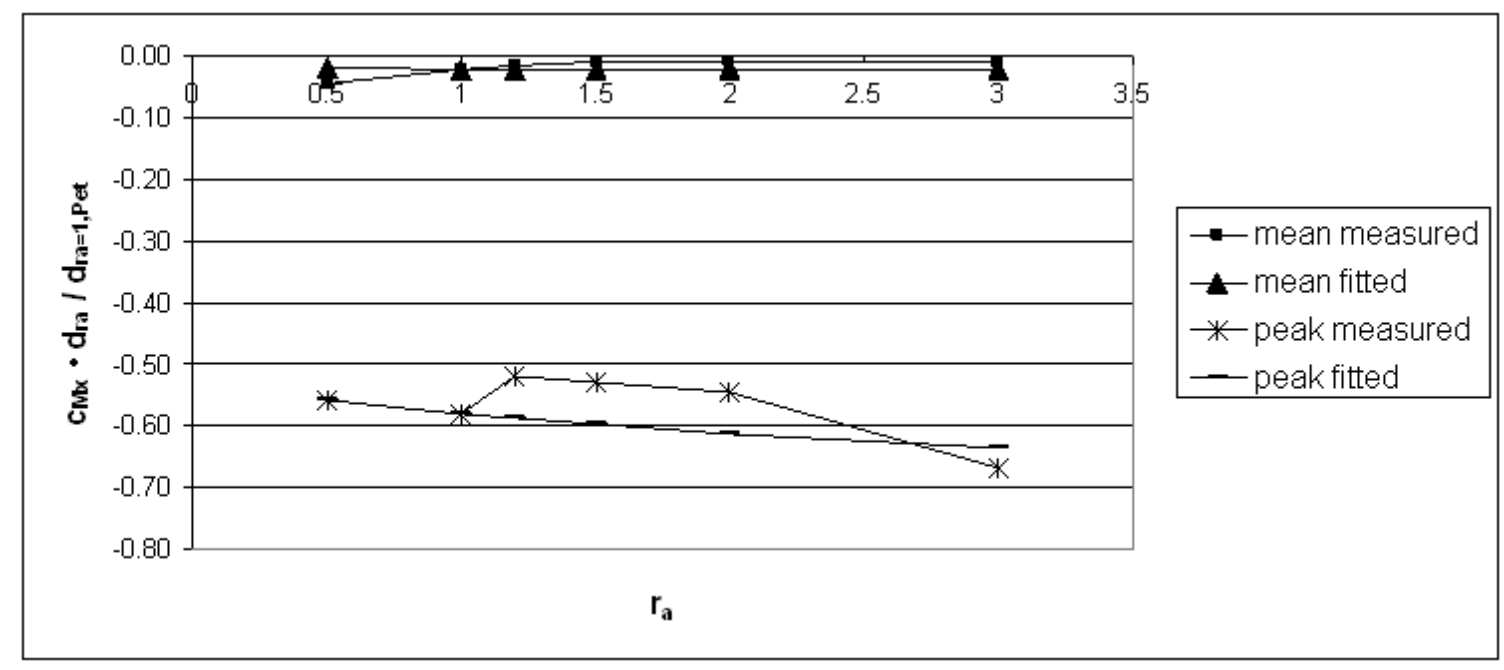

Figure 16: $c M_{x} \cdot d_{r a} / d_{r a=1, \mathrm{Pet}}$ at load case 5

\section{$5.6 M_{H y}$ - hinge moment}

Peterka and Derickson (1992, (4)) assume the hinge moment $M_{H y}$ to be proportional to the chord length $h$ of the heliostat. For load case 2 this fits well to the measurements (figure 17).

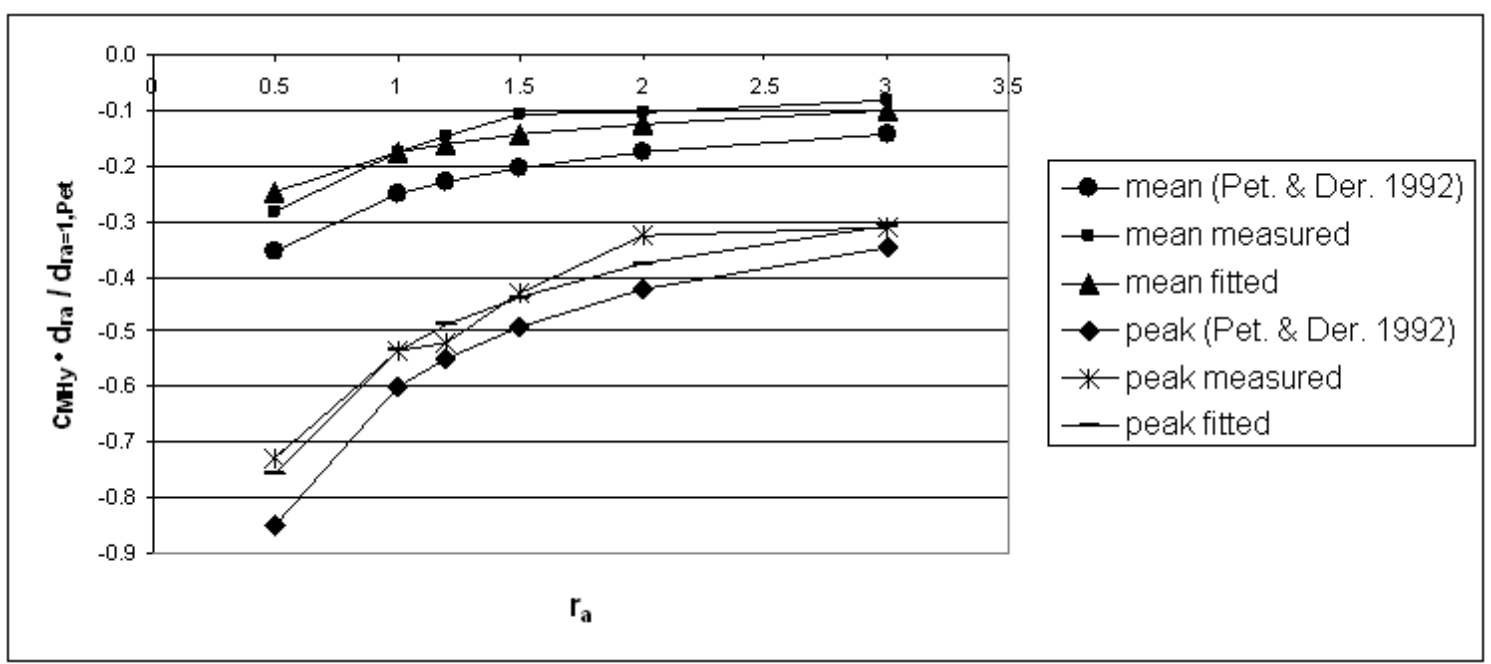

Figure 17: $c_{M H y} \cdot d_{r a} l d_{r a=1, \mathrm{Pet}}$ at load case 2

The reason for this dependency is the almost linear pressure distribution at load case 2 (figure 18 left). For a linear pressure distribution and different aspect ratios the lever arm of the resulting force is proportional to $h$ whereas the value of the force itself remains the same because the mirror area is not varied. Thus all in all $M_{H y}$ is proportional to $h$ (see figure 23). 


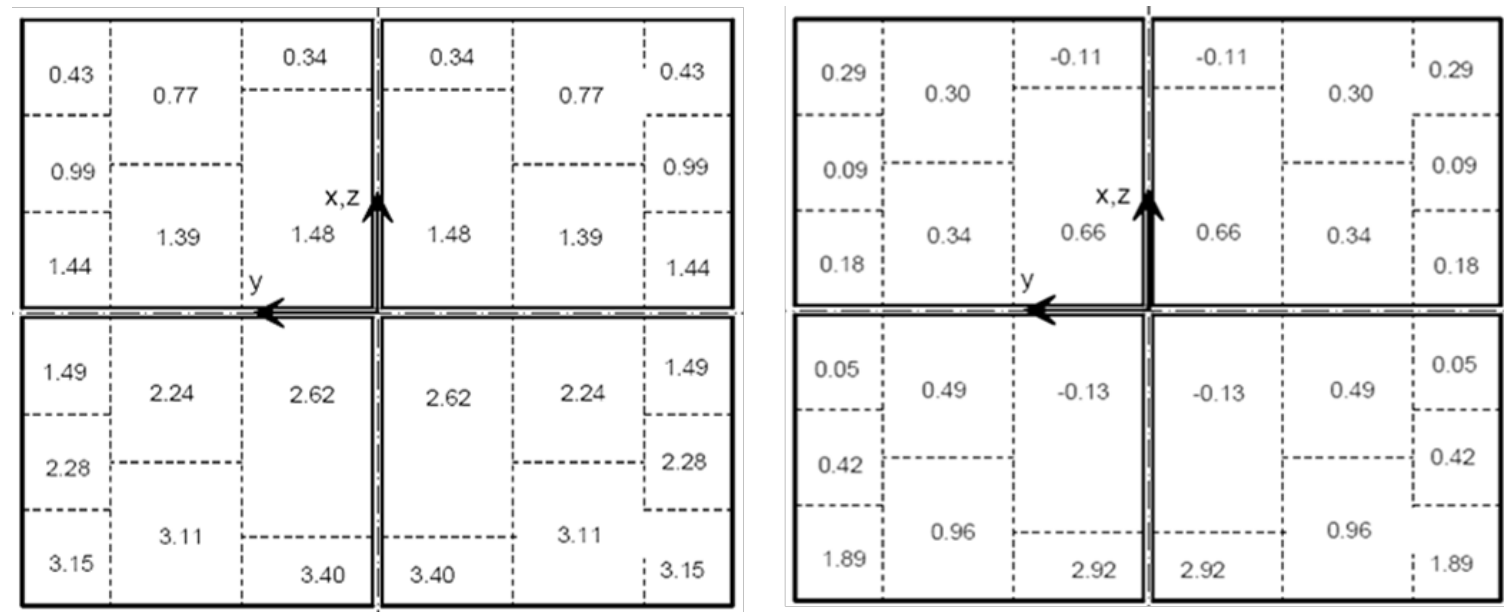

Figure 18: Pressure coefficient distribution for aspect ratio 1.2 at point in time with peak $M_{H y}$ with $\alpha=30^{\circ}$ and $\beta=0^{\circ}$ (load case 2) (left) and $\alpha=0^{\circ}$ and $\beta=0^{\circ}$ (load case 4) (right)

For load case 4 (figure 18 right) the pressure distribution which leads to the peak value of $M_{H y}$ is different to load case 2 (figure 18 left). At the frontal edge a small region of high pressure is measured. Presumably it is caused by a turbulence structure which just hits the mirror plane there. The width of the frontal edge increases with the aspect ratio but the lever arm (distance of the frontal edge to the $y$ axis) decreases (see figure 24). This explains why the aspect ratio dependency of $M_{H y}$ at load case 4 is less pronounced than of Peterka and Derickson (1992, (4)) (figure 19) and at load case 2 (figure 17).

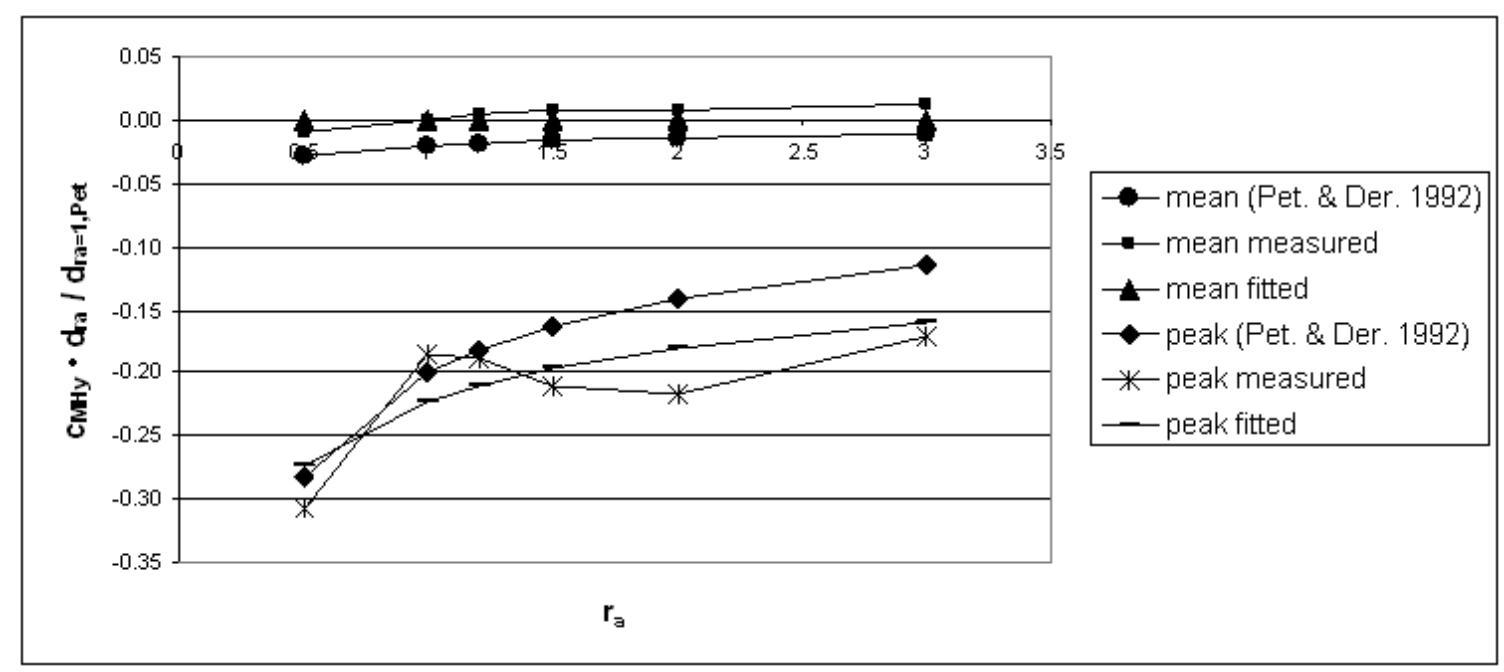

Figure 19: $c_{M H y} \cdot d_{r a} l d_{r a=1, P e t}$ at load case 4

\section{7 $M_{y}$ - moment at pylon feet about $y$ axis}

Peterka and Derickson (1992, (6)) calculated $M_{y}$ by

$$
M_{y}=F_{X} \cdot H+M_{H y} .
$$


For the peak values formula (18) leads to too high results because the peak values of $F_{X}$ and $M_{H y}$ do not appear at the same point in time since they are caused by different flow conditions. This is shown by the comparison of the values of $M_{y}$ calculated by (15) (based on direct measurements) with the values of $M_{y}$ calculated according to (18) (based on $F_{X}$ and $M_{H y}$ ) in figure 21. It explains (additional to the gap effect, see chapter 5.1) the higher peak values of $M_{y}$ of Peterka et al. (1989) at load case 4.

At load case $1 M_{H y}$ is relatively small so that (18) leads to better results and can be simplified to $M_{y} \approx F_{x} \cdot H$. Therefore the modification of the formula of the load coefficient for $M_{y}$ is the same as for $F_{x}$ (see table 2 and figure 20).

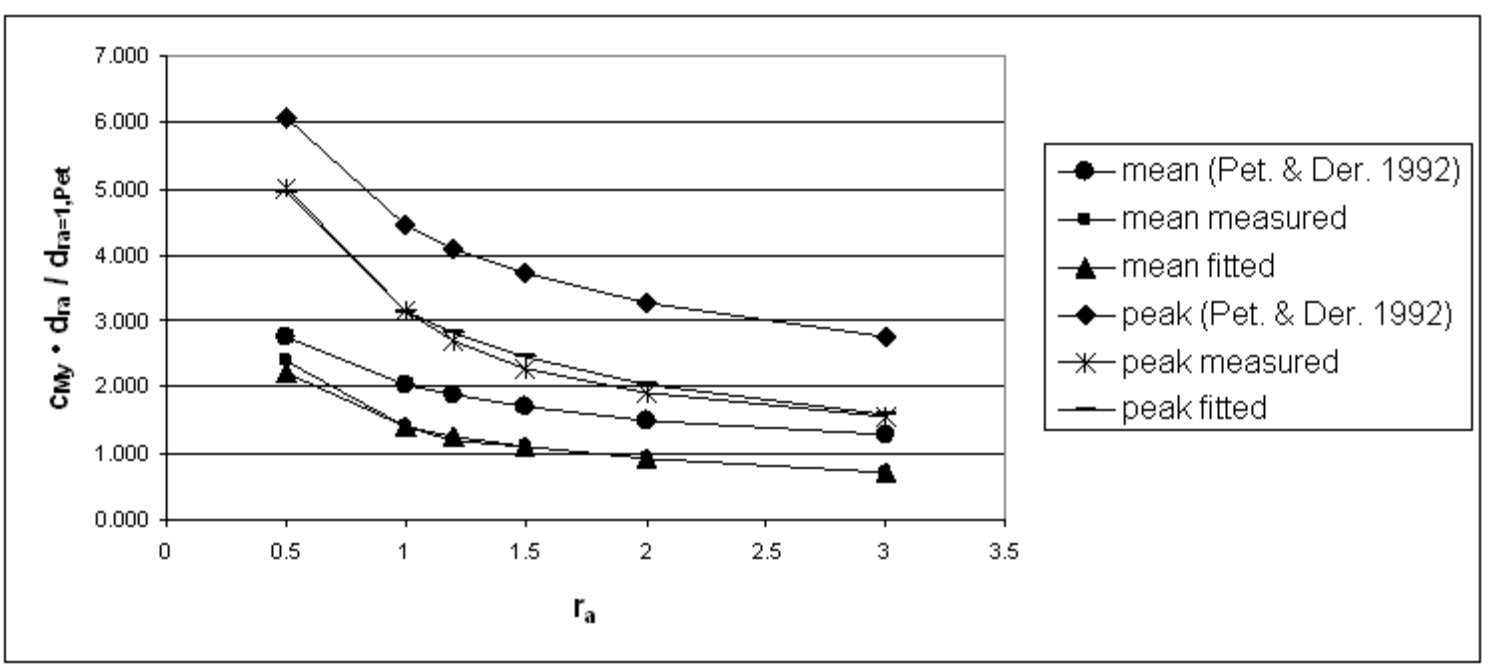

Figure 20: $c_{M y} \cdot d_{r a} l d_{r a=1, \text { Pet }}$ at load case 1

The peak values of $M_{y}$ at load case 4 are caused by similar pressure distributions (not shown here) as the ones of the peak values of $M_{H y}$ (see figure 18 right). Therefore also the aspect ratio dependency of $M_{y}$ is similar to the one of $M_{H y}$ (compare figure 21 and 19). 


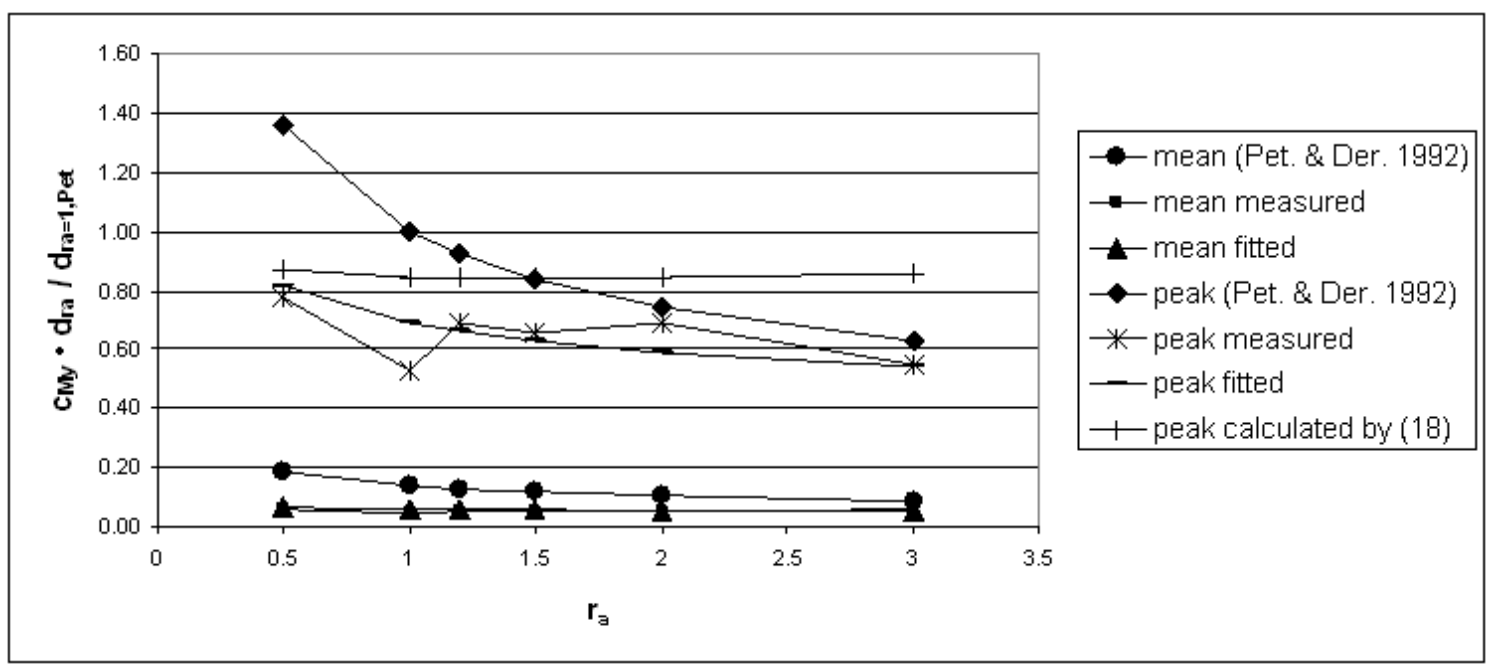

Figure 21: $c_{M y} \cdot d_{r a} / d_{r a=1, P e t}$ at load case 4

\section{$5.8 M_{z}$ - moment about azimuth axis}

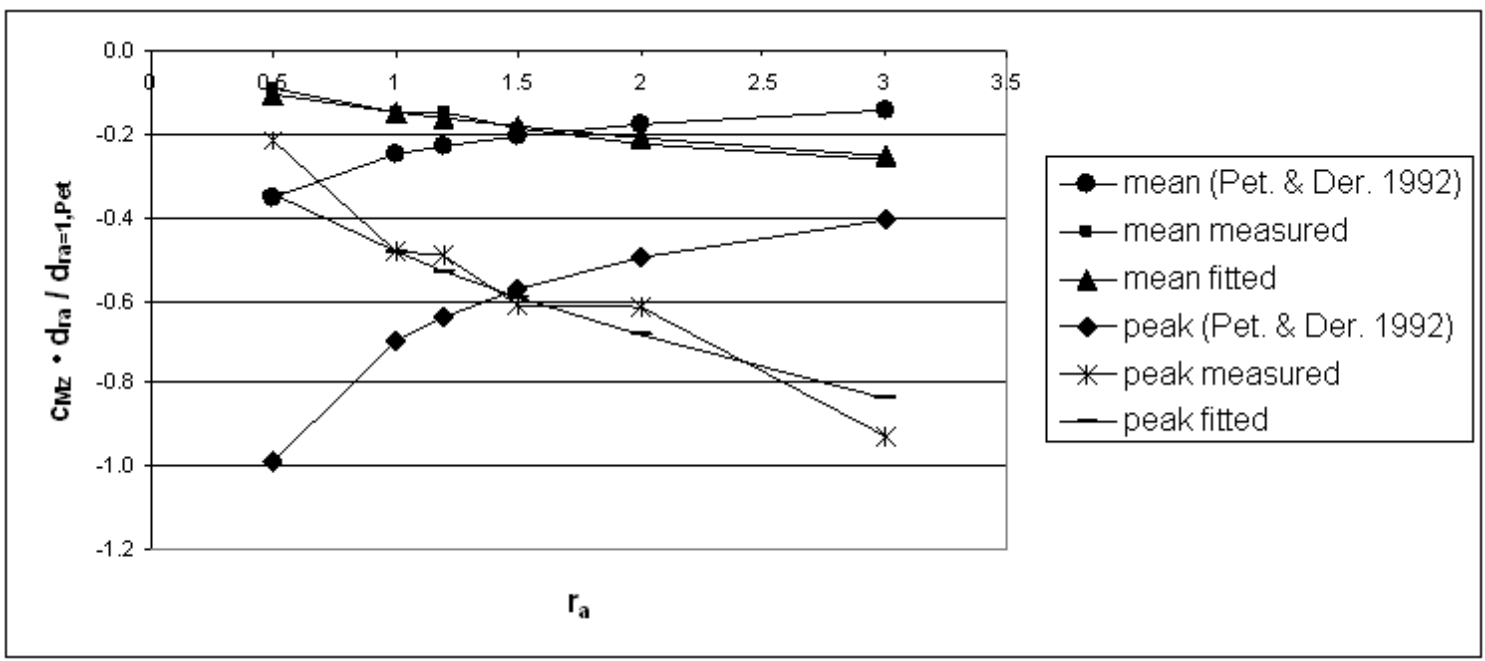

Figure 22: $c_{M z} \cdot d_{r a} / d_{r a=1, P e t}$ at load case 3

As Peterka and Derickson (1992, p. 5, (5)) assume a squared mirror plane they could take for $M_{z}$ the same correlation as for $M_{H y}$ for uniformity reasons. But for varied aspect ratio a dependency on the width $b$ instead of the height $h$ of the mirror plane would be expected which is confirmed by the measurements, see figure 22. The reason for the proportional increase of the absolute values of $M_{z}$ with $b$ is the approximately linear pressure distribution (not shown here) on the whole mirror plane along $b$ comparable to $M_{H y}$ with $h$ at load case 2 (see 5.6). 


\subsection{Comparison of aspect ratio dependencies without impact of wind profile}

In table 2 the quasi aspect ratio dependencies of Peterka and Derickson (1992, p. 10) and the aspect ratio dependencies representing fitting curves to the values of the peak load measurements (see 5.1) of this study are assorted.

Table 2: Aspect ratio dependencies of Peterka and Derickson (1992) and of peak load measurements with various aspect ratios (without impact of wind profile)

\begin{tabular}{|c|c|c|c|c|c|c|c|c|}
\hline $\begin{array}{l}\text { load } \\
\text { case }\end{array}$ & $\alpha$ & $\beta$ & $\begin{array}{c}\text { wind } \\
\text { force }\end{array}$ & $\begin{array}{c}d_{r a} \\
\text { (Peterka and } \\
\text { Derickson, 1992) }\end{array}$ & $\begin{array}{c}d_{r a} \\
\text { according var. } r_{a} \\
\text { measurements }\end{array}$ & $\begin{array}{c}\text { wind } \\
\text { moment }\end{array}$ & $\begin{array}{c}d_{r a} \\
\text { (Peterka and } \\
\text { Derickson, 1992) }\end{array}$ & $\begin{array}{c}d_{r a} \\
\text { according var. } r_{a} \\
\text { measurements }\end{array}$ \\
\hline 1 & $90^{\circ}$ & $0^{\circ}$ & $\boldsymbol{F}_{\boldsymbol{x}}$ & 1 & $1.0 / r_{a}^{0.2}$ & $\boldsymbol{M}_{\boldsymbol{y}}$ & $H$ & $H / r_{a}^{0.2}$ \\
\hline 2 & $30^{\circ}$ & $0^{\circ}$ & $\boldsymbol{F}_{\boldsymbol{x}}$ & 1 & $1.1 / r_{a}^{0.1}$ & $\boldsymbol{M}_{H y}$ & $h$ & $h$ \\
\hline 2 & $30^{\circ}$ & $0^{\circ}$ & $\boldsymbol{F}_{\boldsymbol{z}}$ & 1 & $1.0 / r_{\mathrm{a}}^{0.1}$ & - & & \\
\hline 3 & $90^{\circ}$ & $60^{\circ}$ & - & & & $\boldsymbol{M}_{\boldsymbol{z}}$ & $h$ & $b$ \\
\hline 4 & $0^{\circ}$ & $0^{\circ}$ & $\boldsymbol{F}_{\boldsymbol{x}}$ & 1 & $1.3 \cdot r_{a}^{0.6}$ & $\boldsymbol{M}_{\boldsymbol{H y}}$ & $h$ & $1.2 \cdot h \cdot r_{a}^{0.2}$ \\
\hline 4 & $0^{\circ}$ & $0^{\circ}$ & $\boldsymbol{F}_{\boldsymbol{z}}$ & 1 & $r_{a}^{0.4}$ & $\boldsymbol{M}_{\boldsymbol{y}}$ & $H$ & $1.3 \cdot H \cdot r_{a}^{0.2}$ \\
\hline 5 & $0^{\circ}$ & $90^{\circ}$ & $\boldsymbol{F}_{\boldsymbol{y}}$ & 1 & $1.2 / r_{a}^{0.1}$ & $\boldsymbol{M}_{\boldsymbol{x}}$ & $H$ & $H \cdot r_{a}^{0.5}$ \\
\hline
\end{tabular}

For load cases 1 and 2 the horizontal wind force $F_{x}$ reduces slightly with the aspect ratio as it was measured for free standing plates (Sakamoto and Arie, 1983). For load case 2 this effect is less pronounced as the projected panel area is smaller than at load case 1 which is relevant also for the vertical force $F_{z}$.

$M_{y}$ at load case 1 is the product of the force $F_{x}$ and the accordant lever arm $H$. Therefore the aspect ratio dependency is equal to the aspect ratio dependency of $F_{X}$ multiplied by $H$.

The peak values of $M_{H y}$ at load case 2 and of $M_{z}$ at load case 3 are caused by a linear pressure distribution on the panel (figure 18 left $\left(M_{H_{y}}\right)$ ). Such a pressure distribution leads to a linear aspect ratio dependency with the chord length which is mainly in direction with the flow ( $h$ for load case $2, b$ for load case 3 ) which is explained by figure 23 . 


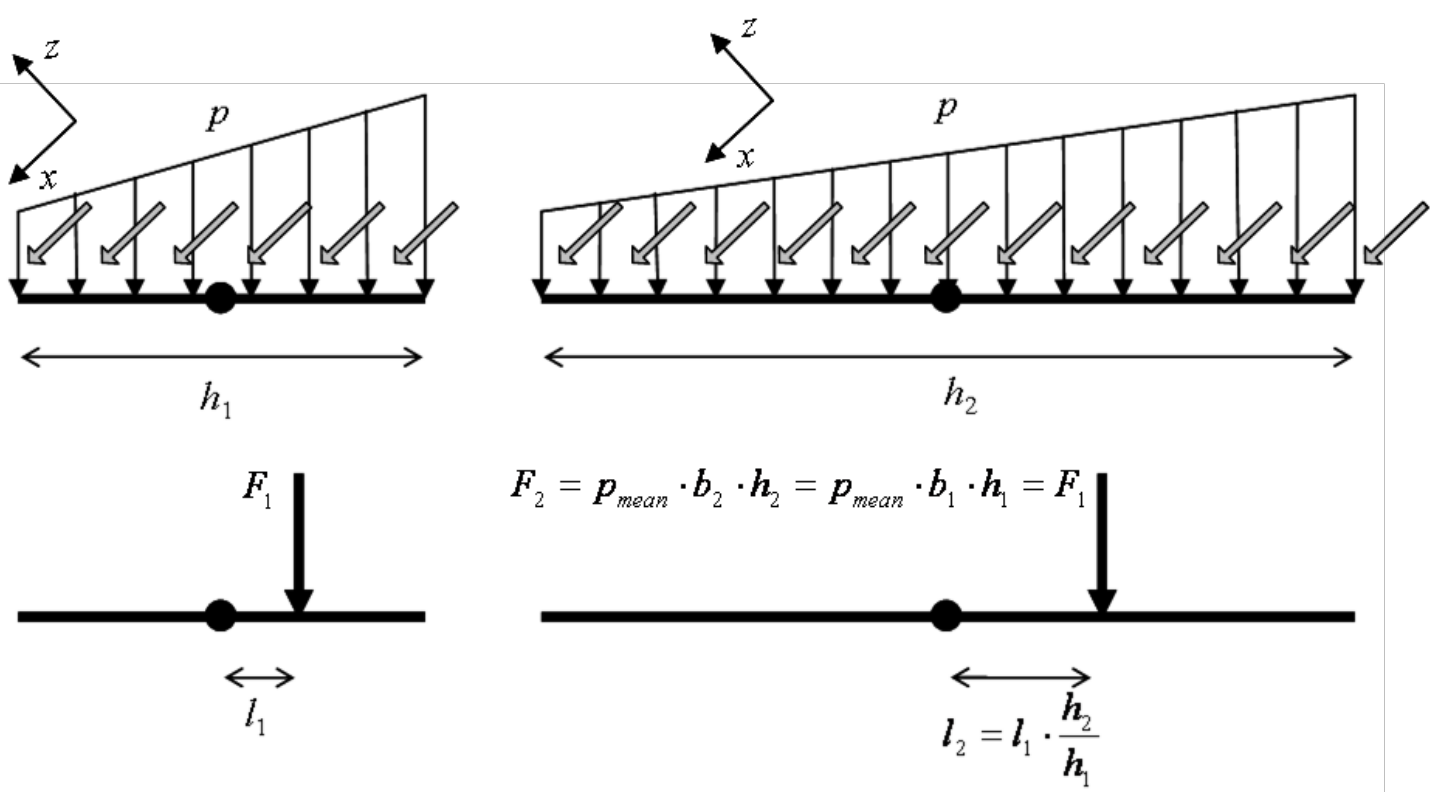

Figure 23: Resulting force and lever arm at linear pressure distribution for higher (left) and smaller (right) aspect ratio at load case 2

The assumptions of Peterka and Derickson (1992) that for $M_{y}$ the elevation axis height $H$ and for $M_{H y}$ the chord length $h$ has to be taken into account as the characteristic lever arm was confirmed for load cases 1 and 2. For $M_{y}$ additionally the aspect ratio dependency of $F_{X}$ is of impact. Accordant to $M_{H y}$ the width $b$ of the panel instead of its height $h$ would have to be used for $M_{z}$ at load case 3 which was confirmed by the measurements.

At load cases 4 and 5 the panel is in horizontal orientation and thus not directed against the main wind direction. But at load case 4 the cross bar is exposed directly to the wind and is of higher impact on the wind loads than for the other load cases. Also the thickness of the panel is of higher impact. At this load case the area of wind attack of cross bar and frontal panel edge increases with increasing aspect ratio which explains the accordant increase of $F_{x}$. At load case 5 the cross bar is in line with the main wind direction and therefore is of no impact. But the height of the pylon and thus its area of wind attack and the edge of the panel seen by the main wind reduce with increasing aspect ratio which explains the reduction of $F_{y}$ with increasing aspect ratio. For the peak values of $F_{z}$ the length of the frontal edge is decisive because of high pressure in this region which leads to increased values for higher aspect ratios.

High pressure at the frontal edge occurs also at the flow conditions which lead to the peak values of $M_{x}, M_{H y}$ and $M_{y}$ at load cases 5 and 4 respectively (see figures 15 right $\left(M_{x}\right)$ and 18 right $\left.\left(M_{H y}\right)\right)$. The impact of it on the aspect ratio dependency is explained by figure 24: The resulting force increases with the aspect ratio while the lever arm decreases by the same ratio. Therefore the wind moment would be constant for varied aspect ratio. 


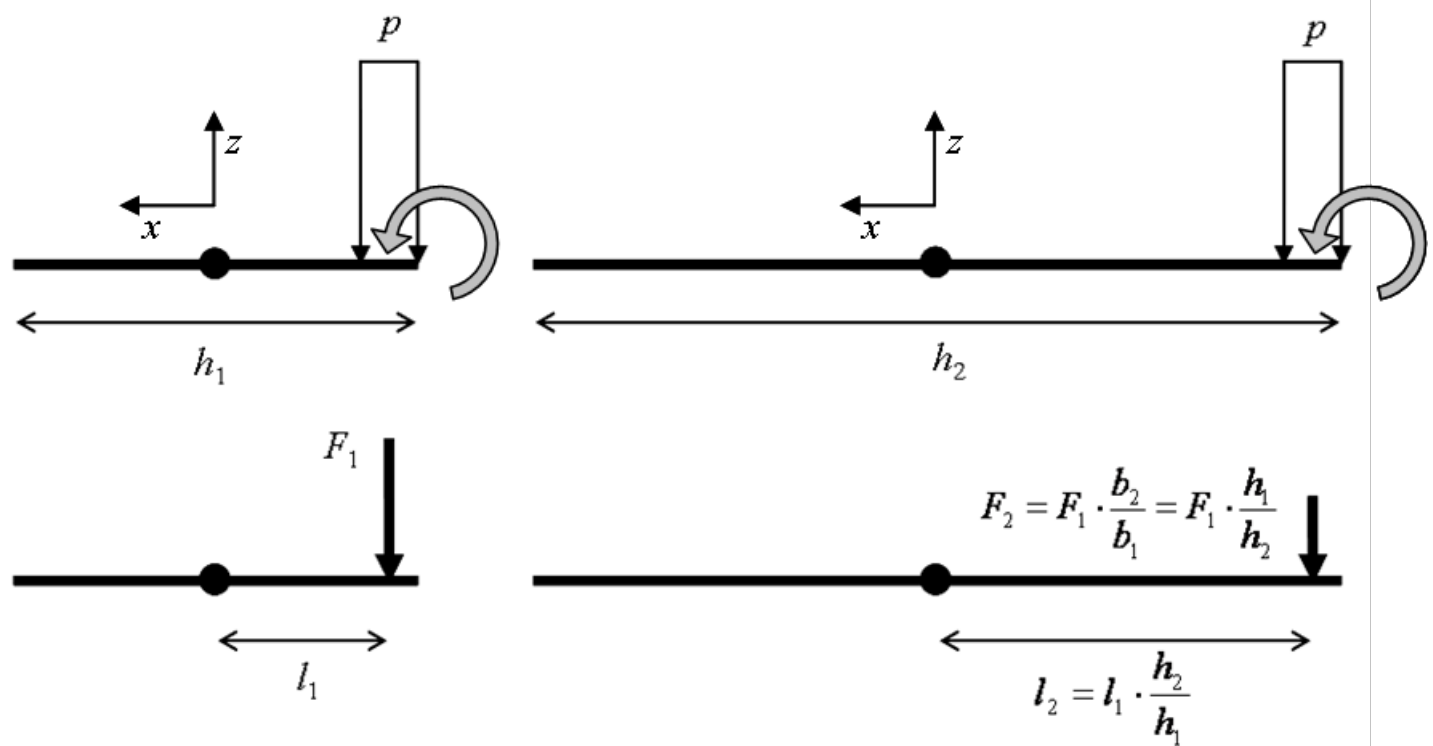

Figure 24: Resulting force and lever arm for increased pressure at one edge for higher (left) and smaller (right) aspect ratio at load case 4

In fact the aspect ratio dependencies are less pronounced as it would be the case if the relevant pressure distributions would be linear which would lead to aspect ratio dependencies similar to the ones implicitly given by Peterka and Derickson (1992), see figures 16, 19 and 21. The accordant characteristic lever arms of Peterka and Derickson (1992) in table $2 h$ and $H$ decrease with the aspect ratio. Therefore correction terms which increase with the aspect ratio (by the power of 0.2 or 0.5 respectively) are multiplied.

\subsection{Total impact of aspect ratio on wind load components inclusive wind profile}

Finally the aspect ratio dependencies are given directly as functions of $r_{a}$ by using

$$
\begin{aligned}
& b=\sqrt{A \cdot r_{a}} \sim \sqrt{r_{a}} \\
& h=\sqrt{\frac{A}{r_{a}}} \sim \frac{1}{\sqrt{r_{a}}} \\
& H \cong \frac{1}{2} h \sim \frac{1}{\sqrt{r_{a}}} .
\end{aligned}
$$

Further more the impact of the solar trackers height is taken into account for all load cases by using (1) with $n=0.15$ and (6) which leads to

$$
p_{d y n} \sim H^{0.3} .
$$


The total impact of the aspect ratio on the wind load components are given in table 3.

Table 3: Impact of aspect ratio on wind load components (influence of wind profile included)

\begin{tabular}{|c|c|c|c|c|c|c|}
\hline load case & $\alpha$ & $\beta$ & wind force & impact $r_{a}$ & wind moment & impact $r_{a}$ \\
\hline 1 & $90^{\circ}$ & $0^{\circ}$ & $\boldsymbol{F}_{\boldsymbol{x}}$ & $\sim 1 / r_{a}^{0.35}$ & $\boldsymbol{M}_{\boldsymbol{y}}$ & $\sim 1 / r_{a}^{0.85}$ \\
\hline 2 & $30^{\circ}$ & $0^{\circ}$ & $\boldsymbol{F}_{\boldsymbol{x}}$ & $\sim 1 / r_{a}^{0.25}$ & $\boldsymbol{M}_{\boldsymbol{H}}$ & $\sim 1 / r_{a}^{0.65}$ \\
\hline 2 & $30^{\circ}$ & $0^{\circ}$ & $\boldsymbol{F}_{\boldsymbol{z}}$ & $\sim 1 / r_{a}^{0.25}$ & - & \\
\hline 3 & $90^{\circ}$ & $60^{\circ}$ & - & & $\boldsymbol{M}_{\boldsymbol{z}}$ & $\sim r_{a}^{0.35}$ \\
\hline 4 & $0^{\circ}$ & $0^{\circ}$ & $\boldsymbol{F}_{\boldsymbol{x}}$ & $\sim r_{a}^{0.45}$ & $\boldsymbol{M}_{\boldsymbol{H}}$ & $\sim 1 / r_{a}^{0.45}$ \\
\hline 4 & $0^{\circ}$ & $0^{\circ}$ & $\boldsymbol{F}_{\boldsymbol{z}}$ & $\sim r_{a}^{0.25}$ & $\boldsymbol{M}_{\boldsymbol{y}}$ & $\sim 1 / r_{a}^{0.45}$ \\
\hline 5 & $0^{\circ}$ & $90^{\circ}$ & $\boldsymbol{F}_{\boldsymbol{y}}$ & $\sim 1 / r_{a}^{0.25}$ & $\boldsymbol{M}_{\boldsymbol{x}}$ & $\sim 1 / r_{a}^{0.15}$ \\
\hline
\end{tabular}

\section{Conclusions}

The wind load components vary partly significantly with the aspect ratio of the panel. Therefore the aspect ratio must be considered at the layout of the components of solar trackers. The main components are the foundation, the pylon, the panel, the elevation and the azimuth drive.

Foundation and pylon must resist the moment at pylon feet $M_{y}$. Especially for upright orientation of the panel (load case 1) but also for the stow position with wind direction along the panel width $b$ (load case 4) $M_{y}$ decreases significantly with the aspect ratio. For stow position with wind direction along with the panel height $h$ (load case 5) only a small reduction with the aspect ratio was measured. But if it is possible for the given site to predict the main wind direction at storm conditions the solar tracker could be turned with the elevation axis orthogonal to the main wind direction and the higher load reduction of load case 4 could be taken into account. Anyhow a higher aspect ratio is advantageous regarding the layout of the foundation and of the pylon which could be designed weaker and would be also shorter.

The elevation drive is loaded by the hinge moment $M_{H y}$. Usually the conditions at which the drive is in operation and maximal loaded (load case 2) are decisive for its layout. Also for the stow position (load case 4) a significant load reduction of $M_{H y}$ with increasing aspect ratio was determined. So also for the elevation drive a high aspect ratio would be favourable.

At stow position the peak value of the moment about the vertical azimuth axis $M_{z}$ is small even for high storm wind speeds. Thus for the azimuth drive the upright orientation of the panel with sideward $\left(30^{\circ}\right)$ wind attack (load case 3 ) is relevant. For load case 3 an increase of $M_{z}$ with increasing aspect ratio was determined. 
This increase is less pronounced compared to the decreases of $M_{H y}$ at load cases 2 and 4 (which are decisive for the layout of the elevation drive) but of more gravity as the azimuth drive is usually more expensive than the elevation drive.

To take the costs of all components of the solar trackers for different aspect ratios into account will lead to a reasonable determination of the aspect ratio.

\section{Acknowledgment}

The investigations were financed by the Bundesministerium für Umwelt, Naturschutz und Reaktorsicherheit (BMU) in the project HydroHelio ${ }^{{ }^{\mathrm{M}}}$ (0325123B) with the objective of the development of a heliostat with hydraulic drive. The authors thank also J. F. Vasquez Arango and the reviewers for their helpful suggestions for improvement of this paper. 


\section{References}

Cook, N.J., Mayne, J.R., 1980. A refined working approach to the assessment of wind loads for equivalent static design. Journal of Wind Engineering and Industrial Aerodynamics, 6, 125-137.

ESDU 89050, 1990. Boundary walls, fences and boardings: mean and peak wind loads and overturning moments. Engineering Science Data, Wind Engineering Series, $2 b$, London.

Fröhlich, J., 2006 ${ }^{1}$. Large Eddy Simulation turbulenter Strömungen, Teubner, Wiesbaden.

Hucho, W.H., 2002. Aerodynamik der stumpfen Körper, Braunschweig/Wiesbaden.

Leder, A., Geropp, D., 1993. Analysis of unsteady flow past bluff bodies. Journal of Wind Engineering and industrial aerodynamics, 49, 329-338.

Letchford, C.W., Holmes, J.D., 1994. Wind loads on free standing walls in turbulent boundary layers. Journal of Wind Engineering and Industrial Aerodynamics, 51, 1-27.

Mathey, F, Cokljat, D., Bertoglio, J.P., Sergent, E., 2006. Assessment of the vortex method for Large Eddy Simulation inlet conditions. Progress in Computational Fluid Dynamics, 6, 58-67.

Peterka, J.A., Derickson R.G., 1992. Wind load design methods for ground based heliostats and parabolic dish collectors. Report SAND92-7009, Sandia National Laboratories, Springfield.

Peterka, J.A., Hosoya, N., Bienkiewicz, B., Cermak, J.E., 1986. Wind load reduction for heliostats, Report SERI/STR-253-2859, Solar Energy Research Institut, Golden, Colorado.

Peterka, J.A., Tan, Z., Cermak, J.E., Bienkiewicz, B., 1989. Mean and Peak Wind Loads on Heliostats. Journal of Solar Energy Engineering, 111, 158-164.

Plate, E.J., 1982. Wind tunnel modeling of wind effects in engineering, in: Plate, E.J. (Ed.), Engineering Meteorology, Studies in Wind Engineering and Industrial Aerodynamics, 1, Elsevier, Amsterdam - Oxford - New York, pp. 573-639.

Sakamoto, H., Arie, M., 1983. Flow around a normal plate of finite width immersed in a turbulent boundary layer. Trans ASME, Journal of Fluids Engineering, 105, 98-104.

Sergent, E., 2002. Vers une Méthodologie de Couplage entre la Simulation des Grandes Echelles et les Modèles Statistiques, PhD Thesis, L'Ecole Centrale de Lyon. 
Spalart, P.R., 2000. Strategies for turbulence modelling and simulations. International Journal of Heat and Fluid Flow, 21, 252-263.

Wang Y.G., Li, Z.N., Gong, B., Li, Q.S., 2008. Wind Pressure and Wind-induced Vibration of Heliostat, Key Engineering Materials, 400-402, 935-940.

Wu, Z., Wang, Z., 2008. Numerical study of wind loads on heliostat. Progress in Computational Fluid Dynamics, 8, 503-509.

Wu, Z., Gong, B., Wang, Z., Li, Z., Zang, C., 2010. An experimental and numerical study of the gap effect on wind load on heliostat, Renewable Energy, $35,797-806$. 


\section{List of tables and figures (all only black-and-white)}

Table 1: Positions of measuring points for facet $A$

Table 2: Aspect ratio dependencies of Peterka and Derickson (1992) and of peak load measurements with various aspect ratios (without impact of wind pofile)

Table 3: Impact of aspect ratio on wind load components (influence of wind profile included)

Figure 1: Heliostat models with aspect ratio 0.5, 1.0, 1.2, 1.5, 2.0 and 3.0

Figure 2: Coordinate system and characteristic lengths (Peterka and Derickson, 1992)

Figure 3: Pressure coefficient distribution for aspect ratio 1.2 at point in time with maximum (left) and minimum (right) peak $M_{H y}$ with $\alpha=90^{\circ}$ and $\beta=0^{\circ}$ (load case 1)

Figure 4: Sketch of heliostat model with aspect ratio 1.2

Figure 5: Schematic section through the atmospheric boundary layer wind tunnel used for the present investigation.

Figure 6: Wind profile (left) and turbulence intensity profile (right) of the simulated atmospheric boundary layer

Figure 7: Model for pressure measurements

Figure 8: Sections of pressure measurements at four facets " $A$ " - "D"

Figure 9: $c_{F x} \cdot d_{r a} / d_{r a=1, \text { Pet }}$ at load case 1

Figure10: $c_{F x} \cdot d_{r a} / d_{r a=1, \text { Pet }}$ at load case 2

Figure 11: $c_{F x} \cdot d_{r a} / d_{r a=1, \text { Pet }}$ at load case 4

Figure 12: $c_{F y} \cdot d_{r a} / d_{r a=1, \text { Pet }}$ at load case 5

Figure 13: $c_{F z} \cdot d_{r a} / d_{r a=1, \text { Pet }}$ at load case 2

Figure 14: $c_{F z} \cdot d_{r a} / d_{r a=1, \text { Pet }}$ at load case 4

Figure 15: Pressure coefficient distribution for aspect ratio 1.2 at point in time with peak $F_{z}$ with $\alpha=0^{\circ}$ and $\beta=0^{\circ}$ (load case 4) (left) and peak $M_{x}$ with $\alpha=0^{\circ}$ and $\beta=90^{\circ}$ (load case 5) (right)

Figure 16: $c M_{x} \cdot d_{r a} / d_{r a=1, \text { Pet }}$ at load case 5

Figure 17: $c_{\text {MHy }} \cdot d_{r a} / d_{r a=1, \text { Pet }}$ at load case 2

Figure 18: Pressure coefficient distribution for aspect ratio 1.2 at point in time with peak $M_{H y}$ with $\alpha=30^{\circ}$ and $\beta=0^{\circ}$ (load case 2) (left) and $\alpha=0^{\circ}$ and $\beta=0^{\circ}$ (load case 4) (right)

Figure 19: $c_{M H y} \cdot d_{r a} / d_{r a=1, \text { Pet }}$ at load case 4

Figure 20: $c_{M y} \cdot d_{r a} / d_{r a=1, \text { Pet }}$ at load case 1 
Figure 21: $c_{M y} \cdot d_{r a} / d_{r a=1, \text { Pet }}$ at load case 4

Figure 22: $c_{M z} \cdot d_{r a} / d_{r a=1, \text { Pet }}$ at load case 3

Figure 23: Resulting force and lever arm at linear pressure distribution for higher (left) and smaller (right) aspect ratio at load case 2

Figure 24: Resulting force and lever arm for increased pressure at one edge for higher (left) and smaller (right) aspect ratio at load case 4 